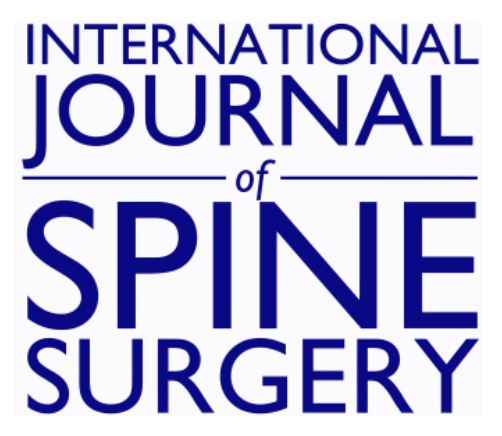

\title{
Difficulties, Challenges, and the Learning Curve of Avoiding Complications in Lumbar Endoscopic Spine Surgery
}

Kai-Uwe Lewandrowski, Albert E. Telfeian, Stefan Hellinger, Jorge Felipe Ramírez León, Paulo Sérgio Teixeira de Carvalho, Max R.F. Ramos, Hyeun Sung Kim, Daniel W. Hanson, Nimar Salari and Anthony Yeung

Int J Spine Surg 2021, 15 (suppl 3) S21-S37

doi: https://doi.org/10.14444/8161

http://ijssurgery.com/content/15/suppl_3/S21

This information is current as of April 26, 2023.

Email Alerts Receive free email-alerts when new articles cite this article. Sign up at: http://ijssurgery.com/alerts 


\title{
Difficulties, Challenges, and the Learning Curve of Avoiding Complications in Lumbar Endoscopic Spine Surgery
}

\author{
KAI-UWE LEWANDROWSKI, MD ${ }^{1,2,3}$; ALBERT E. TELFEIAN, MD, PHD ${ }^{4}$; STEFAN HELLINGER, MD $^{5}$; \\ JORGE FELIPE RAMÍREZ LEÓN , MD ${ }^{6,7}$; PAULO SÉRGIO TEIXEIRA DE CARVALHO, MD, PHD ${ }^{8,9}$; \\ MAX R.F. RAMOS, MD, PHD ${ }^{8,9}$; HYEUN SUNG KIM, MD, PHD ${ }^{10}$; DANIEL W. HANSON, MD ${ }^{11}$; NIMAR SALARI, \\ $\mathrm{MD}^{12} ;$ AND ANTHONY YEUNG, MD ${ }^{12}$ \\ ${ }^{I}$ Staff Orthopaedic Spine Surgeon Center for Advanced Spine Care of Southern Arizona and Surgical Institute of Tucson, Tuscon, Arizona; ${ }^{2}$ Department of \\ Orthopaedics, Fundación Universitaria Sanitas, Bogotá, D.C., Colombia $;{ }^{3}$ Department of Orthopedics, Hospital Universitário Gaffre e Guinle, Universidade Federal \\ do Estado do Rio de Janeiro, Rio de Janeiro, Brazil; ${ }^{4}$ Department of Neurosurgery, Rhode Island Hospital, The Warren Alpert Medical School of Brown University, \\ Providence, Rhode Island; ${ }^{5}$ Department of Orthopedic Surgery, Arabellaklinik, Munich, Germany; ${ }^{6}$ Centro de Columna - Cirugía Minima Invasiva, Clínica Reina \\ Sofía - Clínica Colsanitas, Bogotá, D.C., Colombia; ${ }^{7}$ Fundación Universitaria Sanitas. Bogotá, D.C., Colombia; ${ }^{8}$ Federal University of the State of Rio de Janeiro \\ UNIRIO, Rio de Janeiro, Brazil; ${ }^{9}$ Gaffre e Guinle University Hospital, Rio de Janeiro, Brazil; ${ }^{10}$ Department of Neurosurgery, Nanoori Hospital, Seoul City, Republic of \\ Korea; ${ }^{11}$ Minnesota Spine Institute, Roseville, Minnesota $;{ }^{12}$ Desert Institute for Spine Care, Phoenix, Arizona
}

\begin{abstract}
Spinal endoscopy has the stigma of being reserved for only a few surgeons who can figure out how to master the steep learning curve and develop clinical practice settings where endoscopic spine surgery can thrive. In essence, endoscopic treatment of herniated discs specifically and nerve root compression in the lumbar spine in general amounts to replacing traditional open spine surgery protocols with spinal endoscopic surgery techniques. In doing so, the endoscopic spine surgeon must be confident that the degenerative spine's common painful problems can be handled with endoscopic spinal surgery techniques with at least comparable clinical results and complication rates. In this review article, the authors illustrate the difficulties and challenges of the endoscopic lumbar decompression procedure. In addition, they shed light on how to master the learning curve by systematically looking at all sides of the problem, ranging from the ergonomic aspects of the endoscopic platform and its instruments, surgical access planning, challenging clinical scenarios, complications, and sequelae, as well as the training gaps after postgraduate residency and fellowship programs.
\end{abstract}

Special Issue

Keywords: lumbar endoscopic surgery, complications, sequalae, difficulties, learning curve

\section{INTRODUCTION}

Nowadays, endoscopic spine surgery is better accepted as an alternative to open spinal decompression surgeries. ${ }^{1}$ A new generation of spine surgeons graduating from postgraduate residency and fellowship training programs is now well versed in various forms of minimally invasive spinal surgery techniques. ${ }^{2}$ Typically, these techniques employ multiple forms of tubular and bladed retractor systems that facilitate alternate posterolateral, oblique, and direct lateral approaches to the lumbar spine and replace traditional midline muscle stripping exposures. The transition from open to tubular-retractor-based minimally invasive lumbar spinal surgery using small access portals and an operating microscope is relatively easy because the spinal anatomy is visualized in a magnified manner familiar to most spine surgeons. While the endoscopic working channel can be considered a further miniaturized version of such tubular retractors (Figure 1), the videoendoscopic visualization of the treated pathology is much different. ${ }^{3,4}$ A small optical rod-lens assembly integrated into the endoscope's wall carries a highly magnified and inverted image into the prism housed in the body of the endoscope. The prism projects an upright image into an ocular that can be connected to a standard arthroscopic charge-coupled device video camera (Figure 2). ${ }^{5}$ Typically, the optics are angled between $20^{\circ}$ and $30^{\circ}$, effectively creating a visualization cone larger than the outer diameter of the endoscopic working sheath, particularly when beveled or fenestrated working cannulas are used. The adjunctive use of irrigation fluid improves the clarity of visualization but also creates a distinctive appearance of the painful pathoanatomy that may not be intuitive to untrained spine surgeons. ${ }^{4}$ Familiar anatomical structures such as the spinal nerves, foraminal ligaments, and the dural sac have a different videoendoscopic appearance than 

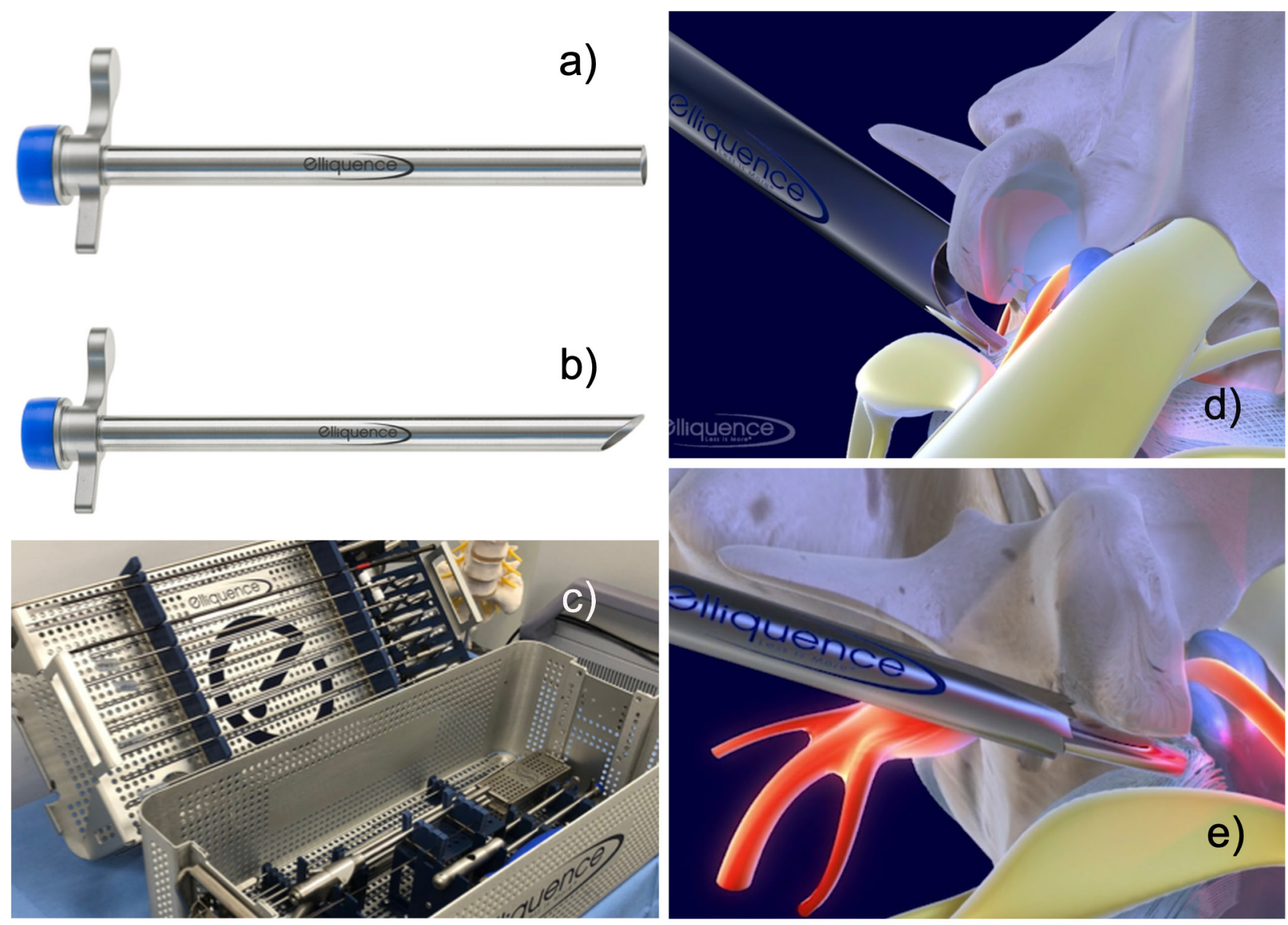

Figure 1. Endoscopic working cannulas resemble small tubular retractors with either 8.0- or 7.5-mm outer diameters and 7.1- or 6.5-mm inner diameters and are $165 \mathrm{~mm}$ in length. The endoscopic working sheath is offered with a straight (A), $40^{\circ}$ beveled (B), or fenestrated tip. Several options are available in a standard lumbar transforaminal endoscopy tray (C). The beveled or fenestrated tip may be used to visualize and retract the exiting nerve root (D). Hydrostatic pressure and irrigation flow can be managed by attaching a plastic seal (blue cap) or by covering the end of the working cannula with the endoscopist's thumb or a Luer lock stopcock when available. Trephines and rasps (E) can be used for a foraminoplasty when needed.

when seen through the operating microscope or with the naked eye.

Endoscopically, the painful pathoanatomy may be seen with great detail and clarity because of the magnified videoendoscopic depiction of the diseased area. Previously underappreciated painful pathology may now be more precisely identified in greater detail and treated in the same operation. ${ }^{6}$ Examples of such painful pathology include annular tears, granulation- or scar tissue, tethered nerve roots, contracted foraminal ligaments, sequestered disc herniations entrapped in the annulus, or inflammatory facet cysts adherent to the dorsal root ganglion of the exiting nerve root. ${ }^{7}$ The irrigated endoscopic procedure also applies low hydrostatic pressure to the surgical area, which aids in hemostasis and tissue dissection. However, it also adds another technical aspect to the procedure: fluid management. Besides being able to recognize painful spinal anatomy, the novice endoscopic spine surgeon has to master 2 additional new skill sets: (1) gaining hand-eye coordination looking at the video- and fluoroscopic monitors instead of at the patient and (2) effectively directing the endoscopic instruments at the target area, all while integrating visual information with tactile feedback obtained during the endoscopic decompression surgery. These procedural elements unique to endoscopic spine surgery constitute what is commonly referred to as the learning curve. ${ }^{8}$ Mastering this learning curve has taken anywhere between 15 and 80 cases. ${ }^{9}$ Depending on comfort and skill level, surgeons may apply different patient selection criteria for the endoscopic decompression operation. ${ }^{10}$ The available equipment and payment coverage in the surgeon's area, or lack thereof, may also go into the preoperative decision-making. ${ }^{11-14}$

The increasing utilization of percutaneous endoscopic lumbar discectomy has also brought to light 

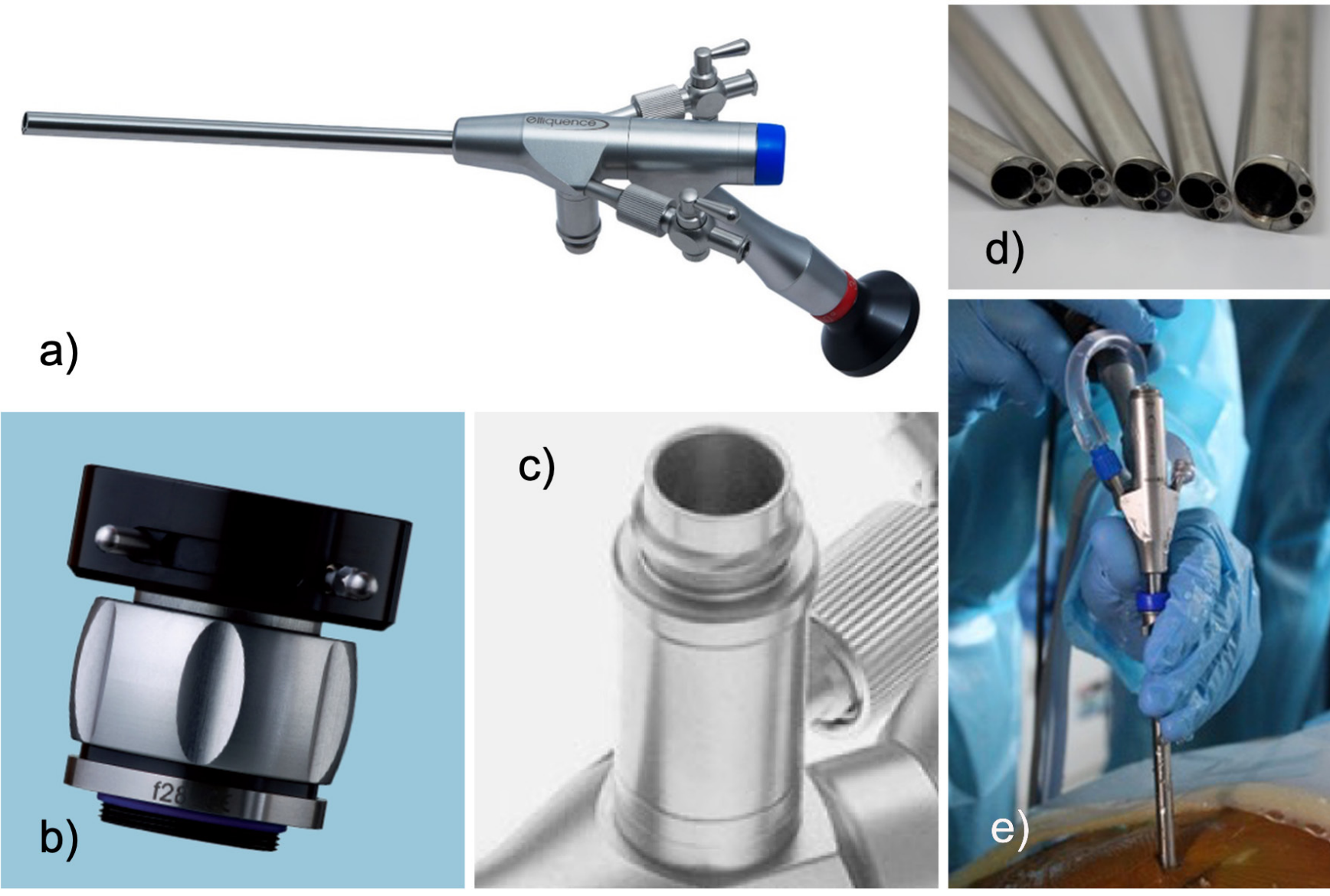

\section{a)}

Figure 2. (A) Oval spinal endoscope $\left(6.9 \times 6.3 \mathrm{~mm}\right.$, length of $177 \mathrm{~mm}, 20^{\circ}$ with one 4.1 -mm oval working channel). A high-definition charge-coupled video camera can be attached to the HD-TV adapter (B). The light cable is connected via a standard coupler (C). Several configurations of the spinal endoscope with small and larger working channels are available, ranging from 3.7 to $6.9 \mathrm{~mm}$. Typically, the lens between the light carriers is embedded in the sidewall of the endoscope (D). The ergonomic design of the lumbar foraminoscopes shown (E) allows the surgeon to rotate the endoscope easily without tangling up light and video cables when attempting to target painful spinal pathology.

its advantages and clinical outcomes. ${ }^{15-22}$ As with any new technology, there has been a surge of utilization followed by a rise in less favorable results and complications, highlighting the procedure's limitations. ${ }^{23-26}$ Percutaneous endoscopic lumbar discectomy, whether in its transforaminal ${ }^{3,10,27-33}$ or interlaminar form, ${ }^{18,34-37}$ has procedure-specific shortcomings and additional limitations dictated by the underlying degenerative disc disease that are worth discussing. In this review article, the authors list the common problems responsible for inferior clinical outcomes, complications, and controversies and technical tips and pearls for resolving them.

\section{Ergonometric Systems and Learning Curve}

Endoscopic instruments are designed around the endoscopic platform to facilitate decompression maneuvers through the small inner working channel of the spinal endoscope. Most contemporary foraminoscopes designed for transforaminal decompression have an internal working channel of $\varnothing 4.3 \mathrm{~mm}$ to accommodate standard neurosurgical instruments, many of which are modified to work through the long endoscopes. Sizable inner diameter endoscopes (i.e., Ø $7.1 \mathrm{~mm}$ ), called stenosis endoscopes, are available for the translaminar endoscopic approaches, such as those employed during interlaminar surgery to speed up the decompression. ${ }^{5}$ The ergonomic design of these instruments is critical to allow the surgeon to use both hands independently and effectively. ${ }^{38}$ For the right-handed surgeon, the endoscope is held in the left hand with the index finger resting on the working channel. The index finger controls the distance of the endoscope from the working channel and, thus, defines the size of the field of view and the hydrostatic water column within the working cannula. The thumb should rest on the working channel or the end cap to control fluid flow and the hydrostatic pressure within the water column of the working sheath at the target area. If available, Luer lock stopcocks at the working channel or the endoscope can also regulate flow and pressure independent of the gravity feed or 

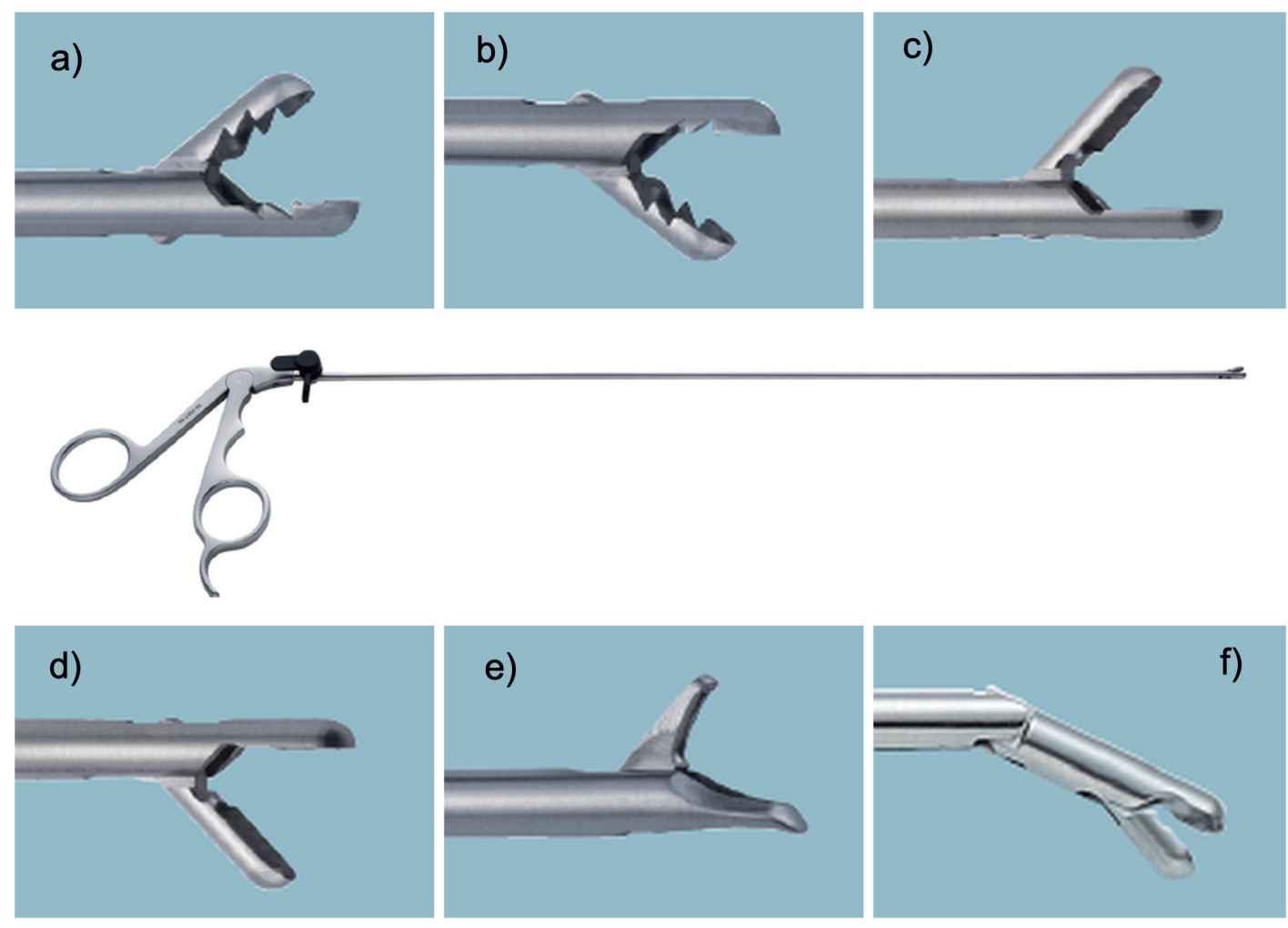

Figure 3. Commonly used grasping forceps designs: (A) 3.0-mm upbiter. (B) 3.5-mm downbiter. (C) 3.5-mm micro spoon upbiter. (D) 3.5-mm micro spoon downbiter. (E) 3.5-mm endoscopic punch. (F) Articulating grasping forceps with ratchet with a 5-mm jaw.

water pump. The latter often have a significant lag. The remaining long, ring, and little fingers rest around the video ocular and camera assembly, allowing the endoscope to be freely rotated to direct it at the target area. Therefore, the right hand is entirely available for introducing long endoscopic instruments (typically 330-370 $\mathrm{mm}$ in length) through the central working channel. The surgeon looks at the video and fluoroscopy screen and only occasionally at the surgical field. While this description of endoscope handling may seem trivial, learning how to use one hand consistently is critical to mastering the learning curve and, in a way, is quite similar to learning a musical instrument. Hence, practicing the endoscopic lumbar decompression surgery in the same choreography and scripted manner is the best way to overcome any initial handling difficulty.

The endoscopic grasping forceps are ergonomically designed with grip handles capable of accommodating all fingers. Typically, the long endoscopic grasping forceps for the lumbar spine allow for $360^{\circ}$ rotation and complete clearance of the grip handle, without obstruction by light cable, video camera, irrigation, or suction tubing attached to the spinal foraminoscope. Commonly used grasping forceps designs are shown in Figure 3. There are various configurations with upbiting or down-biting graspers, spoon cutters, punches, and articulating grasping forceps with ratchets to reach painful pathology not just within the intervertebral disc space, but also distant to it (e.g., downward- or upwardmigrated disc herniations). ${ }^{39-42}$ This combination of specialty endoscopic instruments designed to maximize the benefit of the endoscopy with a scripted step-by-step operation allows the novice endoscopic spine surgeon to master the learning curve quickly and execute modern variations of the surgery for herniated discs and more complex stenosis problems effectively. ${ }^{22,43-48}$

\section{Access Planning, Trajectories, and Learning Curve}

Establishing an access portal is the first essential step in spinal endoscopy. For the interlaminar approach, the initial guidewire is placed via a spinal needle at the trailing edge of the rostral lamina at its junction with the facet joint complex of the surgical level. For the transforaminal approach, the guidewire is advanced via a spinal needle into the triangular safe zone between the exiting and traversing nerve root to access the lateral spinal canal (Figure 4). The optimum angles for access trajectories for the L3-4, L4-5, and L5-S1 levels vary between $10^{\circ}$ and $40^{\circ}$ in the axial plane, $55^{\circ}$ to $65^{\circ}$ in the sagittal plane, and $25^{\circ}$ to $50^{\circ}$ in the coronal plane. ${ }^{49,50}$ 


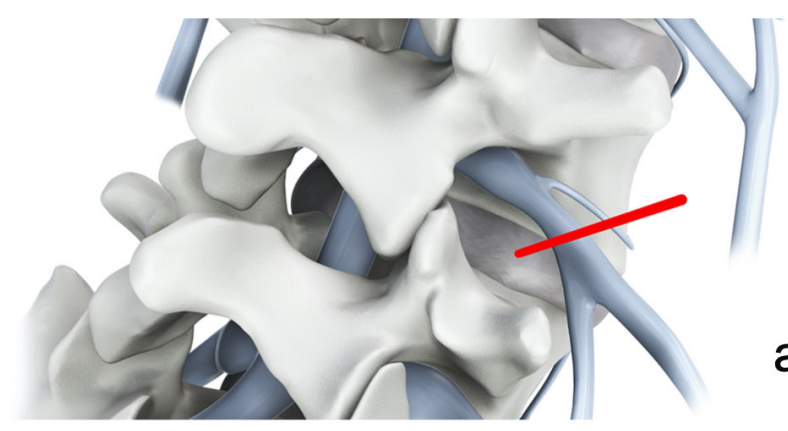

a)
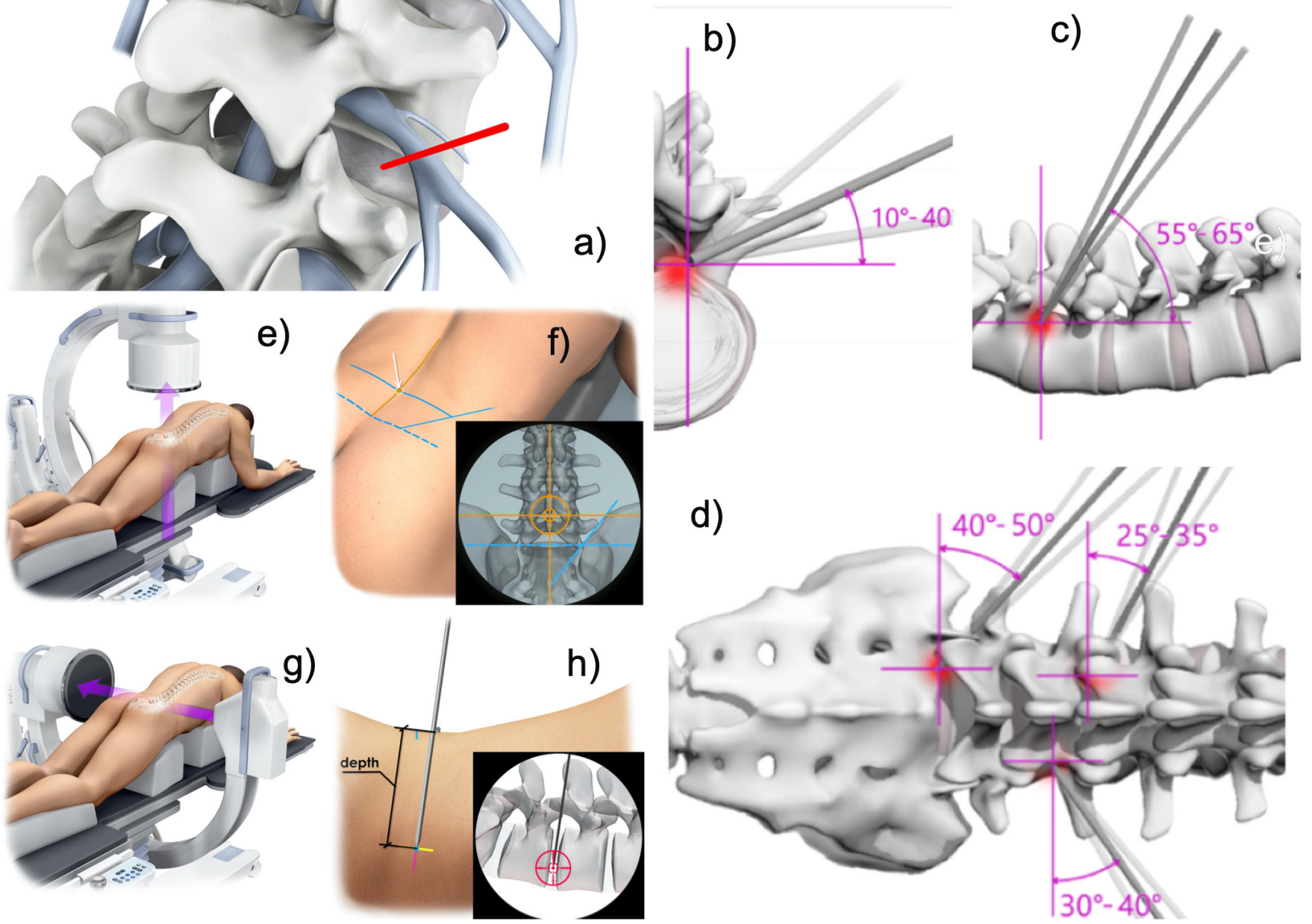

Figure 4. The initial step of the transforaminal endoscopic approach to the lateral spinal canal is to place a guidewire into the triangular safe zone between the exiting and traversing nerve root (A). The optimum access trajectories angles for the L3-4, L4-5, and L5-S1 levels are shown in the axial (B), sagittal (C), and coronal plane (D). It is best to measure these trajectory angles on the patient in the posterior-anterior plane $(E, F)$ and in the lateral plane (G, H). These determined access lines should be drawn on the patient in both the posterior-anterior and lateral fluoroscopic projection $(F, H)$.

The recommended access trajectory angles are depicted in Figure 4. However, these numbers should be verified on preoperative advanced imaging studies, including magnetic resonance imaging or computed tomography scans. Plain film studies of the patient's lumbar spine are essential for understanding the pelvic anatomy to recognize any possible obstruction to the planned endoscopic access by a high-riding ilium, the sacral alar, or transitional anatomy. ${ }^{51}$ The latter can be of significant concern when attempting endoscopic access to the L5-S1 motion segment. ${ }^{52}$ Therefore, the access angles and trajectories should also be directly measured intraoperatively on the patient in the posterior-anterior and lateral fluoroscopic projection to determine the best angle to access the targeted painful spinal pathology. ${ }^{53,54}$ Many patients suffer from multilevel vertical collapse and deformity due to advanced degenerative disease of the intervertebral disc and facet joint complex. ${ }^{6}$ Therefore, more direct lateral or steeper attack angles may be necessary to deal with obstructive access problems caused by hypertrophic facet joints, yellow ligaments, and bony osteophytes. Additional consideration should be given to the location of the compressive pathology in relation to the intervertebral disc and its position in the neuroforamen. ${ }^{6,38}$ The 4-zone classification (Table 1 and Figure 5) by Lee et al

Table 1. Radiological classification of migrated disc herniation according to Lee et al. ${ }^{55}$

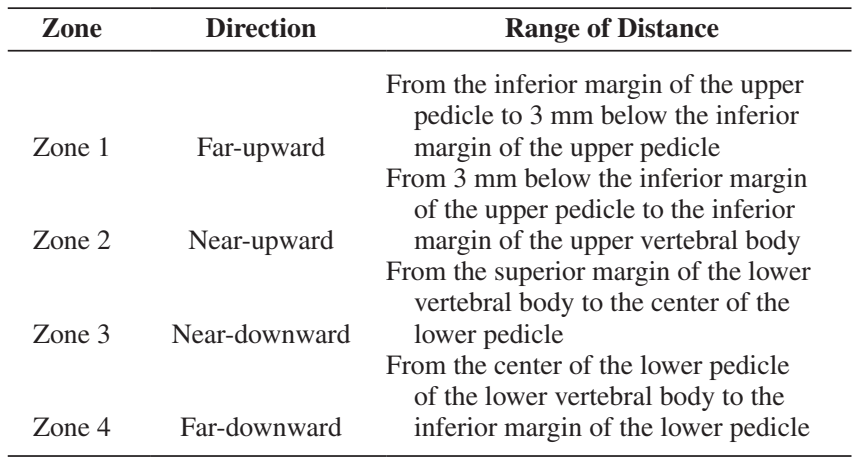



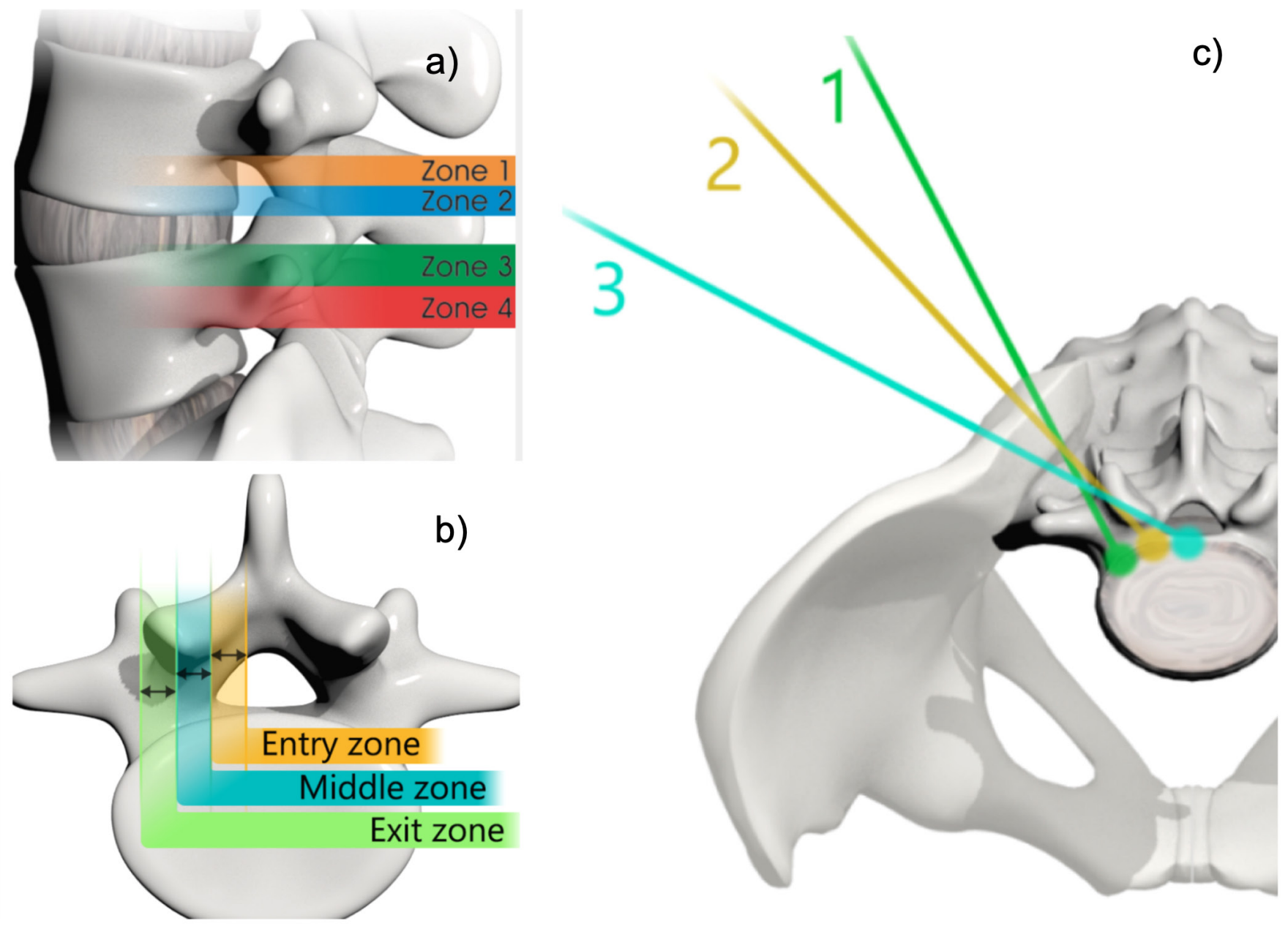

Figure 5. The assessment of cranial-caudal localization of a pathology such as a herniated disc may dictate whether the surgeon should choose a steep or shallow craniocaudal angle (A). Lee et al published a magnetic resonance imaging classification system of herniated discs to direct the endoscopic access. This classification categorizes the disc migration into 4 zones, depending on the direction and distance from the disc space (Table 1). Lee's classification of foraminal stenosis (B) can be used to define the location of the offending bony pathology within the neuroforamen by dividing it from medial to lateral into entry (dura to pedicle), middle (medial pedicle wall to center pedicle), and exit zones (center pedicle to the lateral border of the facet joint). Bony foraminal stenosis in the entry, middle, and exit zones is frequently due to hypertrophy of the superior articular facet, an osteophytic process underneath the pars interarticularis, and a subluxed and hypertrophic facet joint, respectively (Table 2). The skin entry point can be chosen from the midline depending on the location of the herniation in the entry, middle, or exit zone of the neuroforamen ( $\mathrm{B}, \mathrm{C})$. Assessing the pathology on axial views allows the distance of the entry point from the midline to be determined (C).

is a widely accepted method to describe near-migrated (Zones 2 and 3) vs upward (Zone 1) or downward (Zone 4) disc herniations. ${ }^{55}$ Another classification by Lee et al lists the painful compressive spinal pathology location in the lateral recess and neuroforamen as entry, middle, and exit zones (Table 2 and Figure 5). ${ }^{56}$ Conceptualizing the location of the compressive pathology requiring endoscopic removal should be part of any preoperative planning and has been shown to shorten the learning

Table 2. Radiological classification of lumbar neuroforaminal and lateral recess stenosis according to Lee et al ${ }^{55}$ and Hasegawa et al. ${ }^{57}$

\begin{tabular}{|c|c|c|}
\hline Zone & Location & Range of Distance \\
\hline Zone 1 & Entry & From dura to pedicle \\
\hline Zone 2 & Middle & From medial pedicle wall to center pedicle \\
\hline Zone 3 & Exit & $\begin{array}{l}\text { From center pedicle to the lateral border of } \\
\text { the facet joint }\end{array}$ \\
\hline
\end{tabular}

curve among novice endoscopic spine surgeons who are just beginning with the procedure. ${ }^{38}$

\section{Endoscopic Instruments and Learning Curve}

The level of complexity of endoscopic surgery does not just depend on patient-inherent factors or the indication for surgery. ${ }^{58}$ It has been recommended that novice endoscopic spine surgeons commence with easy-totarget herniated discs. ${ }^{9}$ Central or lateral canal spinal stenosis of the lumbar spine requires a more advanced skill set and an array of endoscopic instruments dictated by the sheer amount of bony and soft tissue material that must be removed regardless of the surgical access approach. Discectomy instruments are reasonably straightforward (Figure 3). In patients with advanced lumbar degenerative disease, motorized drills and 


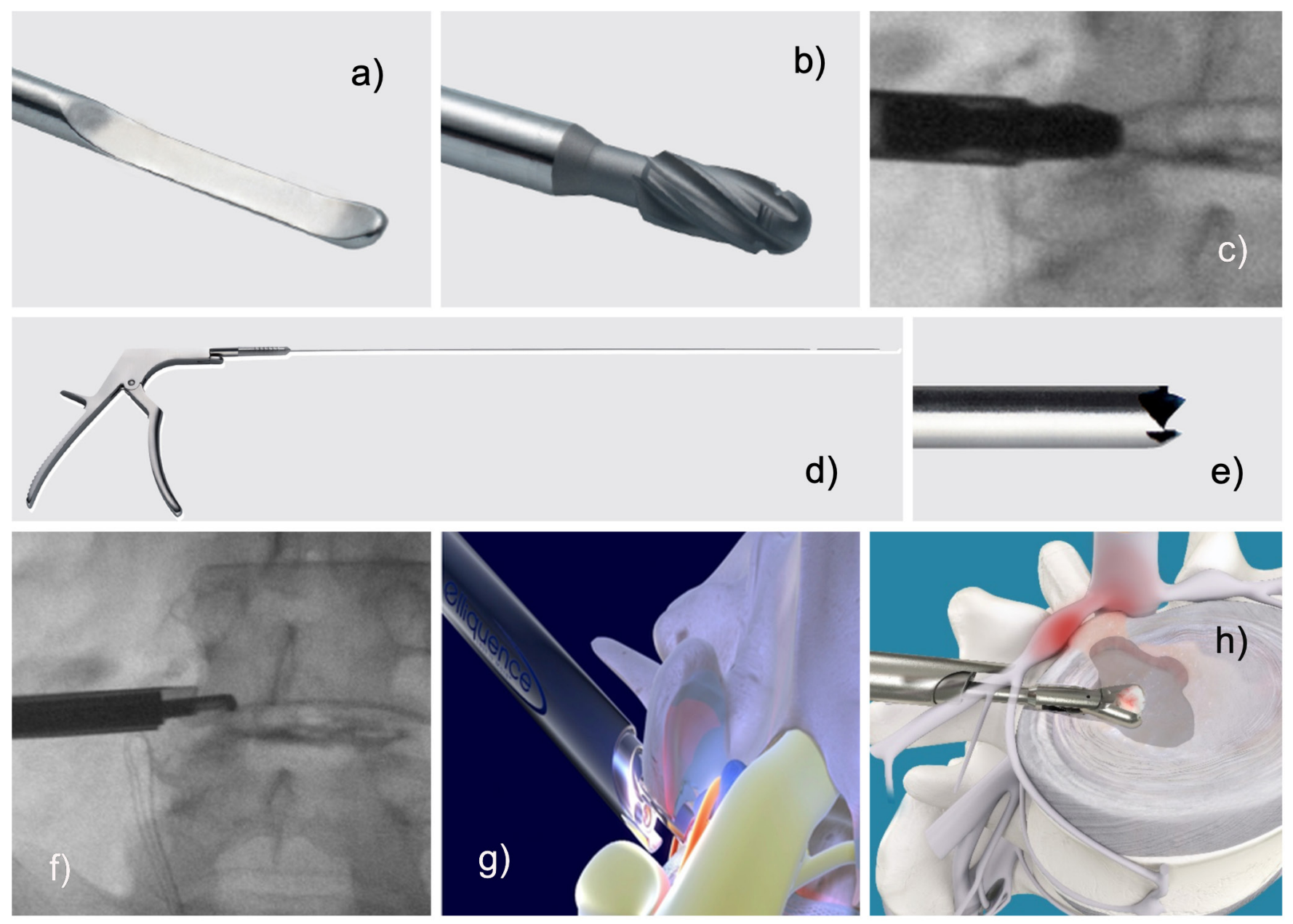

Figure 6. Foraminal decompression can be facilitated with endoscopic dissecting tools (A). Facet raspers (B, C) and Kerrison rongeurs (D, F) are helpful to remove bone and soft tissue. Trephines (E) may also be beneficial. Typically, these maneuvers play out at the superior articular process or the inferior pedicle. Finally, the removal of disc tissue may commence once the intervertebral disc is sufficiently exposed $(\mathrm{H})$. The lateral recess decompression may involve bony resection $(\mathrm{F}$, $\mathrm{G})$ from the superior articular process or the ring apophysis below the traversing nerve root to accomplish adequate decompression.

burrs; endoscopic versions of standard neurosurgical rongeurs, such as a Kerrison, cup, or spoon rongeurs; and chisels are needed to accomplish the goal of the operation (Figure 6). The advantage of the latter manual decompression tools is the associated low risk of neural injury. $^{59}$

In contrast, the use of motorized decompression tools during an interlaminar decompression procedure is associated with a significantly higher rate of incidental durotomies and other complications. ${ }^{60}$ Therefore, Kerrison rongeurs, chisels, and rasps may be the instruments of choice for beginners (Figure 6). Most of these can be inserted directly through the inner working channel of the endoscope, thus allowing decompression under direct visualization. Trephines are also available but are much sharper and often require decompression under fluoroscopic control rather than direct videoendoscopic visualization.
There is no question that power burrs and drills are much more effective in removing bony and soft tissue stenosis than manual instruments, which can be tedious to use. Nonetheless, the authors recommend using them only after sufficient practice with manual endoscopic decompression tools. Understanding the visualized endoscopic pathology shown on the video monitor takes practice. Power instruments also tend to cause a white-out effect due to the amount of debris. Increased bleeding from bony surfaces or epidural veins may also impair visualization, as power tools create turbulence and a pumping effect (Figure 7D). This increased bleeding may overwhelm the endoscopic optical system and lead to red-out. Assessing the extent and location of the compressive pathology (Figure 5) alongside one's skill level and available endoscopic instruments is key to mastering the early learning curve with lumbar endoscopic surgery. 

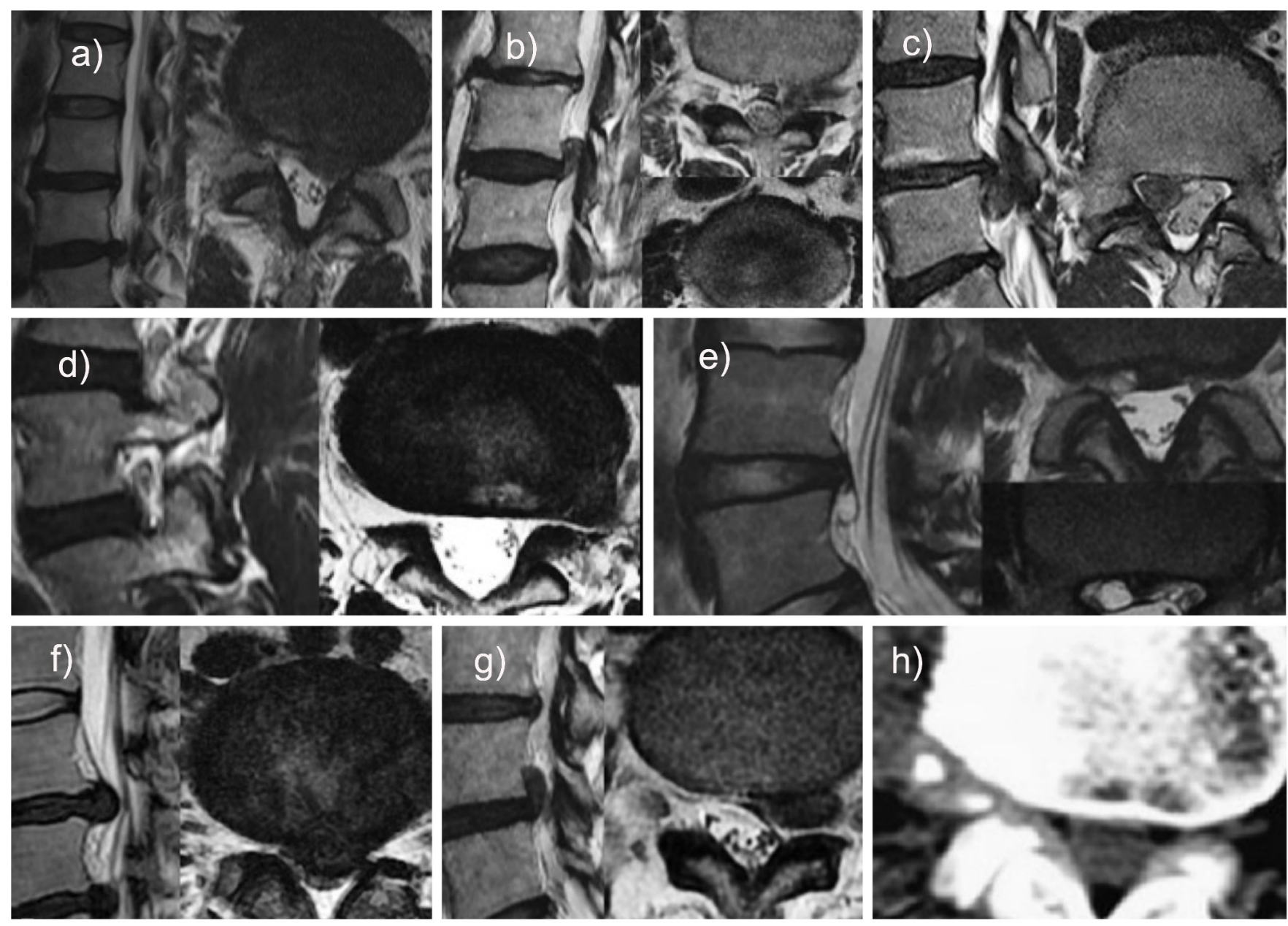

Figure 7. Several challenging case scenarios are shown that the novice spine surgeon should not attempt until a sufficient level of proficiency has been achieved: (A) A paracentral disc herniation should be treated with a targeted fragmentectomy. (B) An upward-migrated disc herniation should be tackled with the exiting nerve root approach, employing a round working channel to protect the exiting root. The axilla should be carefully inspected. (C) A downward-migrated disc herniation is best treated with a targeted fragmentectomy by accessing the epidural space via aggressive foraminoplasty. (D) For far-lateral herniated decompression, the exiting nerve root approach is preferred with a round working channel to protect the exiting root. (E) A facet cyst should be treated via the transforaminal approach with foraminoplasty to identify and remove the stalk of the cyst. (F) A large central herniated disc causing severe central canal compromise should be treated via the outside-in transforaminal approach. Expect multiple fragments. (G) A foraminal herniated disc is also best approached via the exiting nerve root, employing a round working channel. The decompression is complete once the remnant disc behind it is identified. (H) Focally calcified lumbar disc herniation should be removed using the punch and rongeur. Very large calcified disc herniations may have to be drilled down with a shaver or burr.

\section{Challenging Clinical Scenarios}

There are several challenging case scenarios that a novice spine surgeon should attempt until a sufficient level of proficiency has been achieved. These include large paracentral, central, upward- or downwardmigrated, foraminal, or far-lateral disc herniations. Large facet cysts should also not be treated by the beginner. Dural adhesions are common, and dural and nerve root sleeve injuries should be expected. Calcified disc herniations are also potentially difficult to remove, often requiring the use of power instruments. Multifocal calcifications should be expected (Figure 7). Surgeons must determine for themselves whether a given case is beyond their skill set. With practice and more experience, these more significant herniations or severe stenosis cases may be less problematic. Before considering other challenging cases, such as treating fusion complications, adjacent segment disease, spondylolisthesis, resecting tumors, and cement leakage or operating in the thoracolumbar region, the surgeon should consider reaching out to a mentor surgeon who has experience with these types of cases.

\section{Postoperative Complications, Sequelae, and Learning Curve}

In experienced hands, complications are uncommon with endoscopic surgery of the lumbar spine. However, endoscopic techniques carry a subset of iatrogenic complications, including an off-chance of wrong level surgery. Therefore, great care must be given to studying 
the preoperative imaging in the sagittal and axial planes. Radiographic identification of the index level is paramount to this technique and should help avoid wrongsite surgery. Moreover, great care must be taken when inserting and removing the endoscopic instruments. Plunging with the guidewire too deeply may penetrate the anterior annulus and cause vascular or visceral injury. Trephines and reamers may slip out of the target area and cause harm. Aggressive penetration and use of pituitaries and shavers without direct visualization may cause similar injuries and endanger the neural elements and dural sac.

The reported individual and aggregate complication rates have been much lower than the comparable rates for open or minimally invasive translaminar surgery. Some authors reported an aggregate complication rate of $1.42 \%{ }^{61}$ Discounting medical complications, the surgical complication rate was $0.32 \%$, which is 1 magnitude lower than that observed with traditional open lumbar spine surgery. ${ }^{61}$ With the transforaminal technique, approximately $75 \%$ of lumbar endoscopy patients have an entirely uneventful postoperative course. Accounting for all complications, including durotomy $(0.11 \%)$; foot drop $(0.11 \%)$; infection $(0.11 \%)$; worsening of preexisting medical problems $(0.6 \%)$; reherniations of extruded disc fragments $(0.6 \%)$; postoperative sequelae, such as dysesthesia (12.45\%), spinal headaches $(0.44 \%)$, or swelling of the surgical area by infiltration with irrigation fluid (3.75\%); ecchymosis $(0.76 \%)$; failure to cure $(4.35 \%)$; and acute care readmissions $(0.49 \%),{ }^{62}$ a total of $24.04 \%$ of patients were reported to have some adverse event during their postoperative recovery. ${ }^{61}$

The clinically most relevant deviation from an entirely uneventful postoperative course is dysesthesia. This highly manageable and ultimately inconsequential event may benefit from early intervention in an office setting. Such a sequela, defined as unavoidable side effects of an otherwise expertly executed operation, is inevitable and inherent to the lumbar endoscopic procedure. The self-limiting postoperative inflammatory irritation of the dorsal root ganglion (DRG) of the exiting nerve root at the surgical level is the most common sequela. It causes dysesthesia with constant burning leg pain and impaired proprioception and is associated with severe foraminal stenosis. ${ }^{61}$ Occasionally, the latter may cause pseudo-weakness in the muscle groups innervated by the nerve roots stemming from the surgical level. Severely impaired proprioception may lead to poor effort and should be distinguished from true neuropraxia. While the former problem often spontaneously resolves within a few weeks with supportive care measures such as gabapentin, pregabalin, or epidural steroid injections, the latter may require bracing and targeted, muscle-strengthening physical therapy, particularly if the quadriceps muscle is impaired. ${ }^{61}$ Although true weakness with endoscopic decompression surgery is very uncommon, transitory weakness from impaired proprioception can be a nuisance to the patient. Therefore, dysesthesia and neuropraxia should be well explained during the informed consent process. ${ }^{61}$ Reassurance and close follow-up with active management of such postoperative sequelae are part of the solution. Typically, patients' final satisfaction scoring is unaffected by these self-limiting and inconsequential upsets in the postoperative recovery.

A recent multicenter study including 451 patients showed that, contrary to the common belief, dysesthesia rates do not vary much by surgical level. ${ }^{63}$ For example, most endoscopic spine surgeons opine that dysesthesia rates at the L5-S1 level are higher than at any other because the DRG of the exiting L5 and traversing S1 nerve root are in close proximity, with the S1 DRG often being situated in the midsection of the L5-S1 disc space. The increased need for foraminoplasty to deal with bony obstructions of the transforaminal access to the L5-S1 neuroforamen is also a common reason given for stating higher dysesthesia rates at L5-S1. It turns out that these perceived anatomical factors are not as relevant as surgeon skill level. ${ }^{63}$ Dysesthesia rates in patients with excellent Macnab outcomes varied by surgeon from $5 \%$ to $31.1 \%$, with most of the surgeons reporting rates no higher than $9.4 \% .{ }^{63}$ The dysesthesia rates were much higher in patients who reported fair and poor Macnab outcomes and ranged from $16.7 \%$ to $55 \% .{ }^{63}$ Early and persistent DRG irritation was an independent statistically significant predictor of poor functional outcome. ${ }^{63}$

\section{Reherniation and Learning Curve}

The most common reason for early reoperation after endoscopic discectomy is a recurrent disc herniation. The published recurrence rates for open discectomy range from $3.5 \%$ to $5.5 \%{ }^{64,65}$ The published recurrence rate within the first 3 months after endoscopic transforaminal discectomy has been reported at $2.7 \%$ based on 9 recurrences amongst 331 patients with extruded disc herniations. ${ }^{61}$ Reherniations were associated with preserved disc height of greater than $6 \mathrm{~mm}$ at a statistically significant level $(P=0.02)$. Such early recurrence is likely related to procedural details and perhaps surgeon skill level, including incomplete decompression. ${ }^{2}$ At the same time, the most controversial aspect of the 
endoscopic discectomy operation is deciding when to end it. The answer to this seemingly trivial question is not obvious. ${ }^{66,67}$ The authors recommend removing all unstable, delaminated, fissured, and devitalized tissue from the intervertebral disc spaces. ${ }^{68}$ The intradiscal directly visualized "inside-out" technique is most suitable for this step. ${ }^{54,68-76}$ However, no straightforward answer exists to the complex question of whether there are any prognosticators of failure with the endoscopic lumbar discectomy that could be discerned pre- or intraoperatively. Often, an end-stage vacuum disc that is void of any vital and organized nuclear tissue is found. Under fluoroscopic control, these discs can be entirely traversed without difficulty by passing an instrument through a small annular window from the transforaminal access to the patient's opposite side. ${ }^{73}$ Alternatively, the hollow disc space can be directly inspected and visualized with the "inside-out" technique. ${ }^{73}$ This active research areas in endoscopic spine surgery is focused on giving the surgeon a decision algorithm to better define the intraoperative criteria of reliable discectomy or any reconstructive maneuvers, such as annular repair. Ultimately, the goal is to leave the remaining intervertebral disc tissue of the operated diseased segment able to withstand the repetitive compressive loads of daily activities. Avoiding vertical collapse is the best way to prevent the early recurrence of symptoms. Control of the latter is often out of the surgeons' hands, and there may be patient-related factors in play as well. Therefore, giving patients clear postoperative instructions, including short-term bed rest, lifting limitations, and a choreographed walking schedule, is recommended to avoid problems induced by poor patient compliance during the early postoperative recovery. Physical therapy should be cautiously started 6 to 12 weeks after surgery, if at all, as many patients recover without such active exercise programs. Each patient should be monitored closely during the early recovery period for signs and symptoms of recurrent disc herniation.

\section{Durotomy, Neural Injury, and Learning Curve}

Neural injury after lumbar endoscopic spine surgery, although uncommon, will likely occur at one point or another during the career of an endoscopic spine surgeon (Figure 8). ${ }^{77-80}$ These injuries are characterized by motor weakness and sensory loss and are commonly associated with retraction-related neuropraxia. ${ }^{81}$ True surgical transection of traversing or exiting nerve roots during routine lumbar endoscopy is very uncommon, and the authors are unaware of any such reports. Therefore, neuropraxia-related problems will likely resolve spontaneously with supportive care measures, and patients should be reassured. As mentioned previously, neuropraxia should be distinguished from dysesthesia, which frequently occurs after lumbar endoscopy. ${ }^{63,82-85}$ Some surgeons advocate the use of intraoperative neuromonitoring to decrease the rate of postoperative dysesthesia. ${ }^{84}$ In rare cases, neural injury can induce a permanent neurologic deficit, commonly of the exiting root injury, ${ }^{86}$ durotomy, ${ }^{59,61,87}$ a postoperative cauda equina syndrome via epidural hematoma, ${ }^{88}$ motor weakness, and sympathetic injury. ${ }^{78}$ Therefore, formalized postgraduate fellowship training programs for aspiring endoscopic spine surgeons ${ }^{89}$ should emphasize careful nerve root retraction ${ }^{82,90-92}$ and judicious use of thermal radiofrequency ablation to avoid thermal damage. ${ }^{93-95}$

A recent study on the incidence of durotomy during routine lumbar endoscopy polled 93 surgeons with a collective surgical volume of 64470 lumbar endoscopies. There were 689 dural tears. Hence, the incidental durotomy rate was $1.07 \%$. Highlighting the importance of skill level and the learning curve, this study reported that $70 \%$ of the durotomies were encountered by $20.4 \%$ of the surgeons. Without these 19 outlier surgeons, the adjusted durotomy rate was $0.32 \%$. Independent risk factors for dural tears with lumbar endoscopy were stenosis decompression, the use of power burrs, and the interlaminar approach $(P<0.0001) .{ }^{87}$ The most common type of durotomy encountered in the study was medium-sized (less than $10 \mathrm{~mm}$ ) dural tears (52.2\%), followed by small (less than $1 \mathrm{~mm}$ ) pinhole durotomies (46.7\%). These durotomies were associated with rootlet herniations $46.2 \%$ of the time. During the interlaminar approach, the posterior dural sac injury (57\%) occurred more frequently than traversing nerve root injuries (31.2\%). Accounting for the multiple responses in the survey-based study, anterior dural sac durotomies (23.7\%) were less common, and exiting nerve root injuries (10.8\%) were the least common. Over half of responding surgeons did not perform any repair or closure $(52.2 \%)$. Forty percent used sealants. Only $7.8 \%$ performed a repair. Sealants were used in the following order of frequency: DuraSeal $(42.7 \%)$, Tisseel (15.9\%), and Evicel (2.4\%), followed by a generic sealant $(38 \%)$. Some surgeons prefer clipping large durotomies or stuffing the durotomy site with a sealing patch (Figure 9). Bedrest for 24 to 48 hours was instituted by surgeons $48.3 \%$ of the time. An incidental durotomy during routine lumbar endoscopy was inconsequential in $64 \%$ of patients. However, a postoperative cerebrospinal fluid fistula developed in $18 \%$ of durotomy patients. Nonetheless, the absolute incidence of 

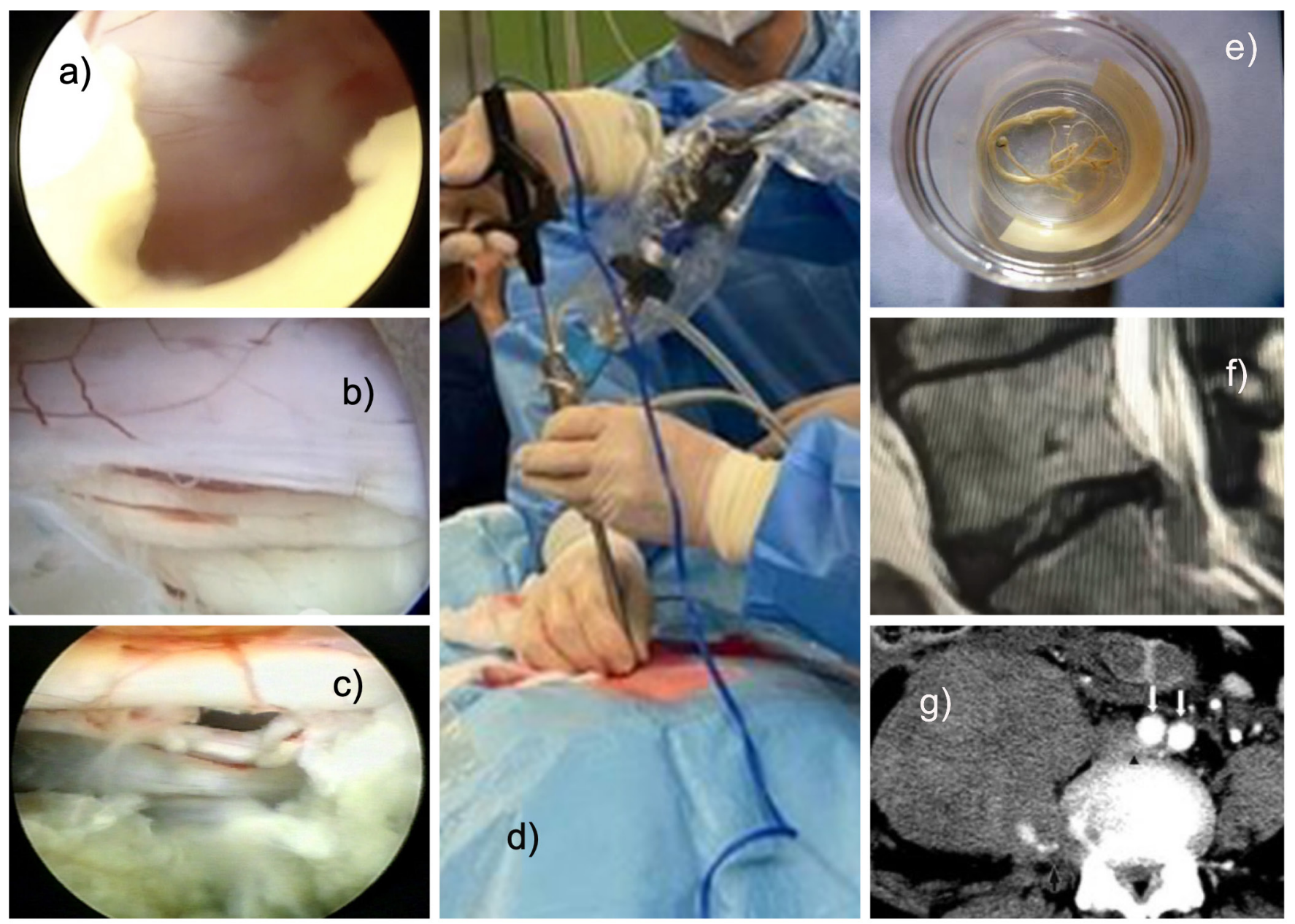

Figure 8. Intraoperative complications are rare during lumbar endoscopic decompression surgery. The interlaminar approach (D) has a higher risk of incidental durotomy $(\mathrm{A}-\mathrm{C})$. It typically occurs with the use of power burrs. During the interlaminar approach, care must be taken not to cause an incidental durotomy when perforating the ligamentum flavum (A). During the transforaminal approach, small incidental durotomies typically occur in the axilla between the exiting and traversing nerve root, the hidden zone of Macnab $(B, C)$. Rarely, true rootlet herniations may occur. Power burrs or drills are notorious for wrapping up rootlets around the spinning tip of the instrument $(E)$. Other examples of postoperative complications include recurrent disc herniation (F) and retroperitoneal hematoma from accidentally severing the segmental vessels located in the lateral aspect of the vertebral bodies of the surgical level (G).

cerebrospinal fluid fistulas was $0.025 \%(16 / 64,470)$, illustrating how rare this undesirable lumbar endoscopy complication truly is. Severe symptoms, including radiculopathy with dysesthesia (12.4\%), sensory loss $(3.4 \%)$, and motor weakness $(2.2 \%)$, were rarely reported by durotomy patients. Avoiding these devastating complications is at the heart of maintaining a highquality endoscopic spine surgery program. However, one should be prepared to manage them, and patients should be thoroughly informed about the pros and cons of endoscopic spine surgery.

\section{Vascular Injury}

One of the dreaded complications of lumbar full endoscopy is an injury to the vascular structures anterior and lateral to the spine. Injuries to the segmental artery and major vessels are of particular concern. Segmental artery injury mainly occurs during transforaminal work, especially when decompressing the exiting nerve root, because the segmental artery passes under the exiting nerve root (Figure 8G). This segmental artery injury may induce serious retroperitoneal hematoma. ${ }^{96}$ The authors recommend that the endoscopic spine surgeon control bleeding from the segmental artery with radiofrequency coagulation. In the authors' experience, conversion to open surgery has not been necessary. If a symptomatic retroperitoneal hematoma should form, it can be treated with open or interventional radiology hematoma evacuation. Observation and supportive care measures are usually sufficient to manage such a retroperitoneal hematoma. ${ }^{97,98}$ The authors are unaware of any publication detailing the application of embolization procedures to manage this unpleasant problem. One of the most significant advantages of the transforaminal posterolateral approach is that 

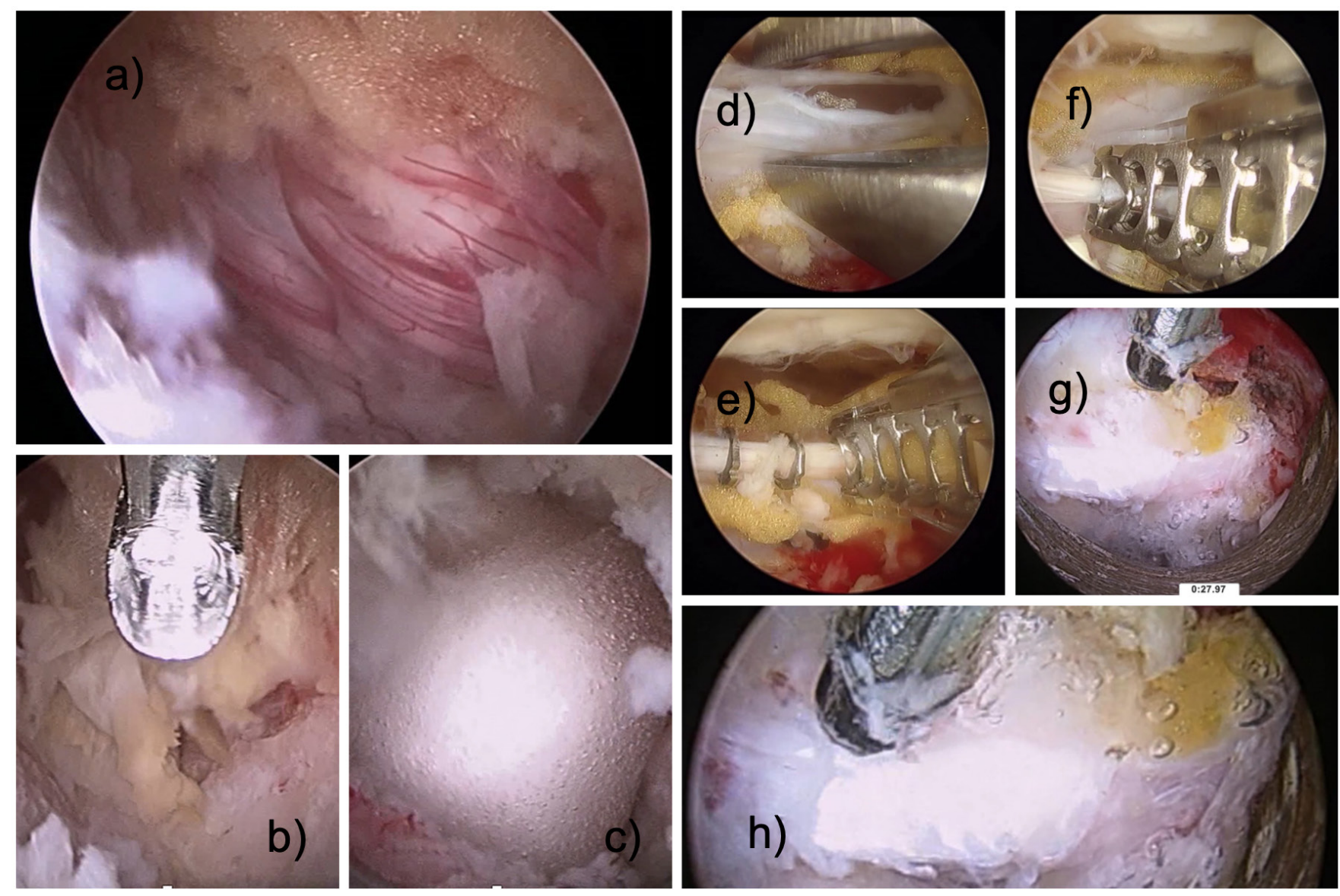

Figure 9. Interlaminar decompression is associated with a high risk of tears in the posterior dural sac (A). The durotomy may occur during the medial facet resection of a hemilaminectomy (B). Durotomies may be treated with a sealant (C), approximated with a bipolar probe (D), and secured with clips (E, F) or stuffed with sealant foam that can be shrunk into the durotomy site $(G, H)$.

the instruments' trajectory makes an injury of the abdominal large vessels very unlikely.

\section{Infection}

Discitis or any other surgical site infection after lumbar endoscopic surgery is extremely rare. One study reported an infection rate of $0.11 \% .^{61}$ First-line treatment should be a minimum 6 week course of intravenous antibiotics. ${ }^{99-101}$ The antibiotics should only be started after a culture biopsy has been obtained to tailor the regimen to the patient's bacterial culture results. ${ }^{102}$ Patients started on empiric antibiotic programs with first- or second-generation cephalosporins may develop antibiotic resistance and a chronic or indolent infection refractory to antibiotic treatment. In some cases, formal surgical debridement is needed to control the infection. An endoscopic lavage of the interior of the infected intervertebral disc is reasonable and can be attempted. ${ }^{103}$ However, open irrigation and debridement may be preferred, particularly if the patient does not improve clinically. Spinal fusion may ultimately be necessary, as infection can rapidly progress the degenerative process at the involved surgical level or may prompt such extensive debridement that it cannot be avoided. Therefore, patients should be thoroughly educated about this devastating complication.

\section{Learning Spinal Endoscopy After Residency and Fellowship}

Postgraduate fellowship training programs teach some of the time-proven minimally invasive spinal surgery techniques but often lag behind this fast-moving field. ${ }^{89}$ A recent survey showed that orthopedic surgeons are more interested in endoscopy $(55.1 \%)$ than neurosurgeons $(33.2 \%)$ and pain management physicians (11.6\%). Reportedly, the trend of anesthesiologists, radiologists, and physical medicine physicians practicing endoscopic surgery has mainly evolved because both orthopedic and neurosurgeons have long neglected it. ${ }^{104}$ Therefore, physicians without formal training in spine surgery, by default, have thrived in this watershed area of spine surgery because of unanswered patient 
demand. ${ }^{105-109}$ The same survey also revealed that the majority $(86 \%)$ of surveyed surgeons were not fellowship trained. ${ }^{2}$ They learned endoscopic spine surgery using multiple avenues such as subspecialty society meetings $(57.3 \%)$, international and national conferences (59.8\%), and workshops (63.1\%). Most of them were autodidacts and self-taught. The ongoing training dilemma created by the lack of accredited formalized programs for endoscopic spine surgery is compounded by court rulings in the United States.

\section{Mastering the Learning Curve}

Once the need is identified, the best course of action for an established spine surgeon-the "apprentice surgeon"-is to identify a "teaching surgeon." Innovators are often open to training other surgeons to achieve validation in their community. ${ }^{9}$ Teaching surgeons are easily recognizable, since many of them strive for recognition in their local communities and by national and international organizations for whom they often organize training courses. Common training models are mentorship (short course or fellowship) or proctorship (prolonged fellowship and hands-on surgical training). The mentorship model works best in a long-distance setup. The teaching surgeon provides expertise in preoperative case discussions to identify the relevant technical pearls on the front end. Postoperative problem-solving on the back end is another potential benefit. The mentorship model is reasonably popular among key opinion leaders, since validation and recognition of their work can be achieved with relatively little effort. The proctorship model is best suited for a local training program within a practice or institution, which allows more one-on-one time for practical, hands-on training. The learning curve and pitfalls of endoscopy can be managed collaboratively at a slower pace, with integration into routine clinical practice as comfort levels increase. Currently, only short instructional courses and symposia are offered by vendors and national and international surgeons' organizations, thus leaving a significant education gap. Mentorship and proctorship programs seem to be the best option for any established spine surgeon to learn spinal endoscopy and overcome the difficulties and challenges of its implementation while keeping complication rates low.

\section{DISCUSSION}

The peer-reviewed published literature has established that complications with lumbar endoscopy procedures are rare. The purpose of this review article was not to relitigate this point but to provide the reader with several illustrative examples of complex cases as well as some technical pearls and tips on how to handle problems that the endoscopic spine surgeon may encounter. When attempting more complex scenarios or operating on patients with prior surgery, regardless of whether it was done open or endoscopically, the endoscopic spine surgeon should be aware of a higher risk of durotomy, nerve root injuries, and complications. Epidural fibrosis, granulation tissue in a previously operated terrain, should be expected and could tether the traversing and exiting nerve roots. Thus, the risk of nerve root injury is higher. Patients should be educated about the higher risk of postoperative dysesthesia. Although typically self-limiting, this unavoidable sequela from an otherwise expertly executed endoscopic spine surgery can be an annoyance to patients. Therefore, preoperative education is critical to avoid unnecessary postoperative emergency room visits, readmissions, or imaging studies that ultimately do not change management but raise the cost of care. Actual nerve root injuries are thankfully uncommon. Patients with neuropraxiarelated motor weakness and sensory and proprioception loss should be reassured. Treatment other than supportive care measures is often not necessary. Patients should be worked up again if other pain generators emerge, as failure to cure or an unfavorable postoperative course is not always related to the previous endoscopic surgery. Other problems may exist in the same patient.

\section{CONCLUSIONS}

Endoscopic spine surgery requires a skill set distinct from what is taught in traditional postgraduate spinal surgery programs. Surgeons who have received training in endoscopic treatment of other body parts and organ systems may have an easier transition to learning spinal endoscopy. More complex clinical cases can be treated with the procedure, increasingly obviating the need for open spine surgery. While there are other translaminar minimally invasive spinal surgery techniques, the endoscopic access and treatment methods offer by far the most direct and least disruptive therapies to treat common painful conditions of degenerative lumbar spine disease.

\section{REFERENCES}

1. Lewandrowski KU, Soriano-Sánchez JA, Zhang X, et al. Regional variations in acceptance, and utilization of minimally invasive spinal surgery techniques among spine surgeons: results of a global survey. J Spine Surg. 2020;6(Suppl 1):S260-S274. doi:10.21037/jss.2019.09.31.

2. Lewandrowski KU, Soriano-Sánchez JA, Zhang X, et al. Surgeon training and clinical implementation of spinal 
endoscopy in routine practice: results of a global survey. J Spine Surg. 2020;6(Suppl 1):S237-S248. doi:10.21037/jss.2019.09.32.

3. Tsou PM, Alan Yeung C, Yeung AT. Posterolateral transforaminal selective endoscopic discectomy and thermal annuloplasty for chronic lumbar discogenic pain: a minimal access visualized intradiscal surgical procedure. Spine J. 2004;4(5):564-573. doi:10.1016/j.spinee.2004.01.014.

4. Yeung AT, Yeung CA. In-vivo endoscopic visualization of patho-anatomy in painful degenerative conditions of the lumbar spine. Surg Technol Int. 2006;15:243-256.

5. Tieber F, Lewandrowski KU. Technology advancements in spinal endoscopy for staged management of painful spine conditions. J Spine Surg. 2020;6(Suppl 1):S19-S28. doi:10.21037/ jss.2019.10.02.

6. Yeung A, Roberts A, Zhu L, Qi L, Zhang J, Lewandrowski KU. Treatment of soft tissue and bony spinal stenosis by a visualized endoscopic transforaminal technique under local anesthesia. Neurospine. 2019;16(1):52-62. doi:10.14245/ns.1938038.019.

7. Lewandrowski KU, Yeung A. Meaningful outcome research to validate endoscopic treatment of common lumbar pain generators with durability analysis. J Spine Surg. 2020;6(Suppl 1):S6-S13. doi:10.21037/jss.2019.09.07.

8. Wang B, Lü G, Patel AA, Ren P, Cheng I. An evaluation of the learning curve for a complex surgical technique: the full endoscopic interlaminar approach for lumbar disc herniations. Spine J. 2011;11(2):122-130. doi:10.1016/j.spinee.2010.12.006.

9. Ransom NA, Gollogly S, Lewandrowski KU, Yeung A. Navigating the learning curve of spinal endoscopy as an established traditionally trained spine surgeon. J Spine Surg. 2020;6(Suppl 1):S197-S207. doi:10.21037/jss.2019.10.03.

10. Dowling Á, Lewandrowski K-U, da Silva FHP, Parra JAA, Portillo DM, Giménez YCP, et al. Patient selection protocols for endoscopic transforaminal, interlaminar, and translaminar decompression of lumbar spinal stenosis. J Spine Surg. 2020;6(Suppl 1):S120-S132. doi:10.21037/jss.2019.11.07.

11. Yeung AT. The evolution of percutaneous spinal endoscopy and discectomy: state of the art. Mt Sinai J Med.2000;67(4):327-332.

12. Wagner R, Haefner M. Indications and contraindications of full-endoscopic interlaminar lumbar decompression. World Neurosurg. 2021;145:657-662. doi:10.1016/j.wneu.2020.08.042.

13. Ruetten S, Komp M, Merk H, Godolias G. Use of newly developed instruments and endoscopes: full-endoscopic resection of lumbar disc herniations via the interlaminar and lateral transforaminal approach. J Neurosurg Spine. 2007;6(6):521-530. doi:10.3171/ spi.2007.6.6.2.

14. Manabe H, Tezuka F, Yamashita K, et al. Operating costs of full-endoscopic lumbar spine surgery in Japan. Neurol Med Chir(Tokyo). 2020;60(1):26-29. doi:10.2176/nmc.oa.2019-0139.

15. Park S-. M, Park J, Jang HS, et al. Biportal endoscopic versus microscopic lumbar decompressive laminectomy in patients with spinal stenosis: a randomized controlled trial. Spine J. 2020;20(2):156-165. doi:10.1016/j.spinee.2019.09.015.

16. Shi R, Wang F, Hong X, et al. Comparison of percutaneous endoscopic lumbar discectomy versus microendoscopic discectomy for the treatment of lumbar disc herniation: a meta-analysis. Int Orthop. 2019;43(4):923-937. doi:10.1007/s00264-018-4253-8.

17. Yang J-S, Chu L, Chen CM, et al. Foraminoplasty at the tip or base of the superior articular process for lateral recess stenosis in percutaneous endoscopic lumbar discectomy: a multicenter, retrospective, controlled study with 2-year follow-up. Biomed Res Int. 2018;2018:7692794. doi:10.1155/2018/7692794.
18. Ruetten S, Komp M, Merk H, Godolias G. Full-endoscopic interlaminar and transforaminal lumbar discectomy versus conventional microsurgical technique. Spine. 2008;33(9):931-939. doi:10.1097/BRS.0b013e31816c8af7.

19. Huang C-M MD. Full-endoscopic procedures versus traditional discectomy surgery for discectomy: a systematic review and meta-analysis of current global clinical trials. Pain Phys. 2016;3;19(3;3):103. doi:10.36076/ppj/2019.19.103.

20. Li M, Yang H, Yang Q. Full-endoscopic technique discectomy versus microendoscopic discectomy for the surgical treatment of lumbar disc herniation. Pain Phys. 2015;18(4):359-363.

21. Ruetten S, Komp M, Merk H, Godolias G. Recurrent lumbar disc herniation after conventional discectomy: a prospective, randomized study comparing full-endoscopic interlaminar and transforaminal versus microsurgical revision. J Spinal Disord Tech. 2009;22(2):122-129. doi:10.1097/ BSD.0b013e318175ddb4.

22. Ruetten S, Komp M, Merk H, Godolias G. Surgical treatment for lumbar lateral recess stenosis with the full-endoscopic interlaminar approach versus conventional microsurgical technique: a prospective, randomized, controlled study. J Neurosurg Spine. 2009;10(5):476-485. doi:10.3171/2008.7.17634.

23. Lin GX, Huang P, Kotheeranurak V, et al. A systematic review of unilateral biportal endoscopic spinal surgery: preliminary clinical results and complications. World Neurosurg. 2019;125:425-432. doi:10.1016/j.wneu.2019.02.038.

24. Yeung AT, Tsou PM. Posterolateral endoscopic excision for lumbar disc herniation: surgical technique, outcome, and complications in 307 consecutive cases. Spine. 2002;27(7):722-731. doi:10.1097/00007632-200204010-00009.

25. Pan M, Li Q, Li S, et al. Percutaneous endoscopic lumbar discectomy: indications and complications. Pain Physician. 2020;23(1):49-56.

26. Arts S, Delye H, van Lindert EJ. Intraoperative and postoperative complications in the surgical treatment of craniosynostosis: minimally invasive versus open surgical procedures. J Neurosurg Pediatr. 2018;21(2):112-118. doi:10.3171/2017.7.PEDS17155.

27. Deng HL, Gao WJ, Zhu JW, Wang XD, Zhou JS. Percutaneous transforaminal endoscopic TESSYS technique for the treatment of bilateral lumbar disc herniation in single segment. Zhongguo Gu Shang. 2018;31(11):1041-1045. doi:10.3969/j. issn.1003-0034.2018.11.011.

28. Gu YT, Cui Z, Shao HW, Ye Y, Gu AQ. Percutaneous transforaminal endoscopic surgery (PTES) for symptomatic lumbar disc herniation: a surgical technique, outcome, and complications in 209 consecutive cases. J Orthop Surg Res. 2017;12(1):25. doi:10.1186/ s13018-017-0524-0.

29. Gadjradj PS, Harhangi BS, Amelink J, et al. Percutaneous transforaminal endoscopic discectomy versus open microdiscectomy for lumbar disc herniation. Spine. 2021;46(8):538-549. doi:10.1097/BRS.0000000000003843.

30. Ning HX, Yuan YW, Zhang QY, Sun ZZ, Ning HY, Wang P. Percutaneous transforaminal endoscopic discectomy and miniincision surgery in the treatment of lumbar intervertebral disc protrusion. J Biol Regul Homeost Agents. 2018;32(3):565-569.

31. Liu C, Zhou Y. Percutaneous endoscopic lumbar diskectomy and minimally invasive transforaminal lumbar interbody fusion for recurrent lumbar disk herniation. World Neurosurg. 2017;98:14-20. doi:10.1016/j.wneu.2016.10.056.

32. Gore S, Yeung A. The "inside out" transforaminal technique to treat lumbar spinal pain in an awake and aware patient under local 
anesthesia: results and a review of the literature. Int J Spine Surg. 2014;8:28. doi:10.14444/1028.

33. Wang YP, Zhang W, An JL, Zhang J, Bai JY, Sun YP. Evaluation of transforaminal endoscopic discectomy in treatment of obese patients with lumbar disc herniation. Med Sci Monit. 2016;22:2513-2519. doi:10.12659/msm.899510.

34. Ma C, Liu G, Xie L, et al. Full-endoscopic interlaminar approach discectomy for central lumbar disc extrusion. Article in Chinese Zhonghua Yi Xue Za Zhi. 2015;95(1807-1810).

35. Chumnanvej S, Kesornsak W, Sarnvivad P, Paiboonsirijit S, Kuansongthum V. Full endoscopic lumbar discectomy via interlaminar approach: 2-year results in Ramathibodi Hospital. J Med Assoc Thai. 2011;94(12):1465-1470.

36. Yadav YR, Parihar V, Namdev H, Agarwal M, Bhatele PR. Endoscopic interlaminar management of lumbar disc disease. $J$ Neurol Surg A Cent Eur Neurosurg. 2013;74(2):77-81. doi:10.105 5/s-0032-1333127.

37. Hwang JH, Park WM, Park CW. Contralateral interlaminar keyhole percutaneous endoscopic lumbar surgery in patients with unilateral radiculopathy. World Neurosurg. 2017;101:33-41. doi:10.1016/j.wneu.2017.01.079.

38. Lewandrowski KU, Yeung A. Lumbar endoscopic bony and soft tissue decompression with the hybridized inside-out approach: a review and technical note. Neurospine. 2020;17(Suppl 1):S34-S43. doi:10.14245/ns.2040160.080.

39. Sang PM, Zhang M, Chen BH. Treatment of migrated lumbar disc herniation with percutaneous endoscopic lumbar discectomy and target foraminoplasty. Zhongguo Gu Shang. 2018;31(4):302-305. doi:10.3969/j.issn.1003-0034.2018.04.002.

40. Eun SS, Lee SH, Erken HY. Transforaminal percutaneous endoscopic lumbar diskectomy for downmigrated disk herniations: lever-up, rotate, and tilt technique. J Neurol Surg A Cent Eur Neurosurg. 2018;79(2):163-168. doi:10.1055/s-0037-1608837.

41. Kim HS, Adsul N, Kapoor A, et al. A mobile outside-in technique of transforaminal lumbar endoscopy for lumbar disc herniations. JoVE. 2018;(138). doi:10.3791/57999.

42. Heo DH, Lee DK, Lee DC, Kim HS, Park CK. Fully endoscopic transforaminal lumbar discectomy for upward migration of upper lumbar disc herniation: clinical and radiological outcomes and technical considerations. Brain Sci. 2020;10(6):E363. doi:10.3390/ brainsci10060363.

43. Shin SH, Bae JS, Lee SH, Keum HJ, Kim HJ, Jang WS. Transforaminal endoscopic decompression for lumbar spinal stenosis: a novel surgical technique and clinical outcomes. World Neurosurg X. 2018;114:e873-e882. doi:10.1016/j.wneu.2018.03.107.

44. Ahn Y, Keum HJ, Lee SG, Lee SW. Transforaminal endoscopic decompression for lumbar lateral recess stenosis: an advanced surgical technique and clinical outcomes. World Neurosurg. 2019;125:e916-e924. doi:10.1016/j.wneu.2019.01.209.

45. Wang YP, Zhang W, Li BL, Sun YP, Ding WY, Shen Y. Suprapedicular foraminal endoscopic approach to lumbar lateral recess decompression surgery to treat degenerative lumbar spinal stenosis. Med Sci Monit. 2016;22:4604-4611. doi:10.12659/ msm.901686.

46. Wu F, Kong W, Liao W, et al. Percutaneous total endoscopic resection of partial articular processes for treatment of lateral crypt stenosis and lumbar spinal stenosis: technical report and efficacy analysis. Biomed Res Int. 2018;2018:9130182. doi:10.1155/2018/9130182.

47. Kashlan ON, Kim HS, Khalsa SSS, et al. Percutaneous endoscopic contralateral lumbar foraminal decompression via an interlaminar approach: 2-dimensional operative video. Operative Neurosurgery. 2019. doi:10.1093/ons/opz162.

48. Hwa Eum J, Hwa Heo D, Son SK, Park CK. Percutaneous biportal endoscopic decompression for lumbar spinal stenosis: a technical note and preliminary clinical results. J Neurosurg Spine. 2016;24(4):602-607. doi:10.3171/2015.7.SPINE15304.

49. Yeung AT, Yeung CA. Advances in endoscopic disc and spine surgery: foraminal approach. Surg Technol Int. 2003;11:255-263.

50. Ruetten S, Hahn P, Oezdemir S, et al. The full-endoscopic uniportal technique for decompression of the anterior craniocervical junction using the retropharyngeal approach: an anatomical feasibility study in human cadavers and review of the literature. J Neurosurg Spine. 2018;29(6):615-621. doi:10.3171/2018.4.SP INE171156.

51. Patgaonkar P, Datar G, Agrawal U, et al. Suprailiac versus transiliac approach in transforaminal endoscopic discectomy at L5-S1: a new surgical classification of L5-iliac crest relationship and guidelines for approach. J Spine Surg. 2020;6(S1):S145-S154. doi:10.21037/jss.2019.09.14.

52. Bai J, Zhang W, Wang Y, et al. Application of transiliac approach to intervertebral endoscopic discectomy in L5/S1 intervertebral disc herniation. Eur J Med Res. 2017;22(1):14. doi:10.1186/ s40001-017-0254-0.

53. Lewandrowski KU. "Outside-in" technique, clinical results, and indications with transforaminal lumbar endoscopic surgery: a retrospective study on 220 patients on applied radiographic classification of foraminal spinal stenosis. Int J Spine Surg. 2014;8:26. doi:10.14444/1026.

54. Lewandrowski KU. The strategies behind "inside-out" and "outside-in" endoscopy of the lumbar spine: treating the pain generator. J Spine Surg. 2020;6(S1):S35-S39. doi:10.21037/ jss.2019.06.06.

55. Lee S, Kim SK, Lee SH, et al. Percutaneous endoscopic lumbar discectomy for migrated disc herniation: classification of disc migration and surgical approaches. Eur Spine J. 2007;16(3):431-437. doi:10.1007/s00586-006-0219-4.

56. Lee CK, Rauschning W, Glenn W. Lateral lumbar spinal canal stenosis: classification, pathologic anatomy and surgical decompression. Spine. 1988;13(3):313-320. doi:10.1097/00007632198803000-00015.

57. Hasegawa T, An HS, Haughton VM, Nowicki BH. Lumbar foraminal stenosis: critical heights of the intervertebral discs and foramina. A cryomicrotome study in cadavera. J Bone Joint Surg Am. 1995;77(1):32-38.

58. Lewandrowski KU, Á D, de Carvalho PST, et al. Indication and contraindication of endoscopic transforaminal lumbar decompression. World Neurosurg. 2021;145:631-642. doi:10.1016/j. wneu.2020.03.076.

59. Telfeian AE, Shen J, Ali R, Oyelese A, Fridley J, Gokaslan ZL. Incidence and implications of incidental durotomy in transforaminal endoscopic spine surgery: case series. World Neurosurg. 2020;134:e951-e955. doi:10.1016/j.wneu.2019.11.045.

60. Lewandrowski KU, Hellinger S, De Carvalho PST, et al. Dural tears during lumbar spinal endoscopy: surgeon skill, training, incidence, risk factors, and management. Int J Spine Surg. 2021;15(2):280-294. doi:10.14444/8038.

61. Lewandrowski KU. Incidence, management, and cost of complications after transforaminal endoscopic decompression surgery for lumbar foraminal and lateral recess stenosis: a value proposition for outpatient ambulatory surgery. Int J Spine Surg. 2019;13(1):53-67. doi:10.14444/6008. 
62. Lewandrowski KU. Readmissions after outpatient transforaminal decompression for lumbar foraminal and lateral recess stenosis. Int J Spine Surg. 2018;12(3):342-351. doi:10.14444/5040.

63. Lewandrowski KU, Á D, Calderaro AL, et al. Dysethesia due to irritation of the dorsal root ganglion following lumbar transforaminal endoscopy: analysis of frequency and contributing factors. Clin Neurol Neurosurg. 2020;197:106073. doi:10.1016/j. clineuro.2020.106073.

64. Abdu RW, Abdu WA, Pearson AM, Zhao W, Lurie JD, Weinstein JN. Reoperation for recurrent intervertebral disc herniation in the spine patient outcomes research trial. Spine. 2017;42(14):1106-1114. doi:10.1097/BRS.0000000000002088.

65. Heindel P, Tuchman A, Hsieh PC, et al. Reoperation rates after single-level lumbar discectomy. Spine. 2017;42(8):E496-E501. doi:10.1097/BRS.0000000000001855.

66. Onik GM, Kambin P, Chang MK. Minimally invasive disc surgery. nucleotomy versus fragmentectomy. Spine (Phila Pa 1976). 1997;22(7):827-828; . doi:10.1097/00007632-199704010-00024.

67. Chen SH MDet al. Using percutaneous endoscopic outside-in technique to treat selected patients with refractory discogenic low back pain. Pain Phys. 2019;2(22.2):187-198. doi:10.36076/ $\mathrm{ppj} / 2019.22 .187$.

68. Lewandrowski KU, León JFR, Yeung A. Use of "InsideOut" Technique for direct visualization of a vacuum vertically unstable intervertebral disc during routine lumbar endoscopic transforaminal decompression-a correlative study of clinical outcomes and the prognostic value of lumbar radiographs. Int J Spine Surg. 2019;13(5):399-414. doi:10.14444/6055.

69. Lewandrowski KU, Ransom NA, Ramírez León JF, Yeung A. The concept for a standalone lordotic endoscopic wedge lumbar interbody fusion: The LEW-LIF. Neurospine. 2019;16(1):82-95. doi:10.14245/ns.1938046.023.

70. Anda S, Støvring J, Rø M. CT of extraforaminal disc herniation with associated vacuum phenomenon. Neuroradiology. 1988;30(1):76-77. doi:10.1007/BF00341949.

71. Chevrot A, Pillon B, Revel M, Moutounet J, Pallardy G. The radiological phenomenon of lumbar vacuum-disc (author's transl). Article in French J Radiol Electrol Med Nucl. 1978;59:267-270.

72. Lee CH, Cho JH, Hyun SJ, Yoon SH, Kim KJ, Kim HJ. Symptomatic gas-containing herniated disc with the vacuum phenomenon: mechanism and treatment. Neurol Med Chir(Tokyo). 2012;52(2):106-108. doi:10.2176/nmc.52.106.

73. Lewandrowski KU, Zhang X, Ramírez León JF, de Carvalho PST, Hellinger S, Yeung A. Lumbar vacuum disc, vertical instability, standalone endoscopic interbody fusion, and other treatments: an opinion based survey among minimally invasive spinal surgeons. J Spine Surg. 2020;6(Suppl 1):S165-S178. doi:10.21037/ jss.2019.11.02.

74. Pak KI, Hoffman DC, Herzog RJ, Lutz GE. Percutaneous intradiscal aspiration of a lumbar vacuum disc herniation: a case report. HSS J. 2011;7(1):89-93. doi:10.1007/s11420-010-9168-x.

75. Schweitzer ME, el-Noueam KI. Vacuum disc: frequency of high signal intensity on T2-weighted MR images. Skeletal Radiol. 1998;27(2):83-86. doi:10.1007/s002560050342.

76. Söffler C, Karpenstein H, Kramer M. The intervertebral vacuum phenomenon as a computed-tomographic finding in the dog and its significance as an indicator for surgical treatment of vertebral disc herniations. Article in German Tierarztl Prax Ausg K Kleintiere Heimtiere. 2014;42:88-93.

77. Abe M, Takata Y, Higashino K, et al. Foraminoplastic transforaminal percutaneous endoscopic discectomy at the lumbosacral junction under local anesthesia in an elite rugby player. J Med Invest. 2015;62(3-4):238-241. doi:10.2152/ jmi.62.238.

78. Hua W, Tu J, Li S, et al. Full-endoscopic discectomy via the interlaminar approach for disc herniation at L4-L5 and L5-S1. Medicine. 2018;97(17):e0585. doi:10.1097/ MD.0000000000010585.

79. Chen X, Qin R, Hao J, et al. Percutaneous endoscopic decompression via transforaminal approach for lumbar lateral recess stenosis in geriatric patients. Int Orthop. 2019;43(5):1263-1269. doi:10.1007/s00264-018-4051-3.

80. Qin R, Liu B, Hao J, et al. Percutaneous endoscopic lumbar discectomy versus posterior open lumbar microdiscectomy for the treatment of symptomatic lumbar disc herniation: a systemic review and meta-analysis. World Neurosurg. 2018;120:352-362. doi:10.1016/j.wneu.2018.08.236.

81. Kambin P, O'Brien E, Zhou L, Schaffer JL. Arthroscopic microdiscectomy and selective fragmentectomy. Clin Orthop Relat Res. 1998;(347):150-167.

82. Cho JY, Lee SH, Lee HY. Prevention of development of postoperative dysesthesia in transforaminal percutaneous endoscopic lumbar discectomy for intracanalicular lumbar disc herniation: floating retraction technique. Minim Invasive Neurosurg. 2011;54(5-6):214-218. doi:10.1055/s-0031-1287774.

83. Li Z, Hou S, Shang W, Cao Z, Zhao H. Percutaneous lumbar foraminoplasty and percutaneous endoscopic lumbar decompression for lateral recess stenosis through transforaminal approach: Technique notes and 2 years follow-up. Clin Neurol Neurosurg. 2016;143:90-94. doi:10.1016/j.clineuro.2016.02.008.

84. de Carvalho PST, Ramos MRF, da Silva Meireles AC, et al. Feasibility of using intraoperative neuromonitoring in the prophylaxis of dysesthesia in transforaminal endoscopic discectomies of the lumbar spine. Brain Sciences. 2020;10(8):522. doi:10.3390/ brainsci10080522.

85. Kim HS, Kim JY, PH W, Jang IT. Effect of dorsal root ganglion retraction in endoscopic lumbar decompressive surgery for foraminal pathology: a retrospective cohort study of interlaminar contralateral endoscopic lumbar foraminotomy and discectomy versus transforaminal endoscopic lumbar foraminotomy and discectomy. World Neurosurg. 2021;148:e101-e114. doi:10.1016/j. wneu.2020.12.176.

86. Choi I, Ahn JO, So WS, Lee SJ, Choi IJ, Kim H. Exiting root injury in transforaminal endoscopic discectomy: preoperative image considerations for safety. Eur Spine J. 2013;22(11):2481-2487. doi:10.1007/s00586-013-2849-7.

87. Lewandrowski KU, Hellinger S, De Carvalho PST, et al. Dural tears during lumbar spinal endoscopy: surgeon skill, training, incidence, risk factors, and management. Int J Spine Surg. 2021;15(2):280-294. doi:10.14444/8038.

88. Ahn DK, Lee JS, Shin WS, Kim S, Jung J. Postoperative spinal epidural hematoma in a biportal endoscopic spine surgery. Medicine (Baltimore). 2021;100(6):e24685. doi:10.1097/ MD.0000000000024685.

89. Chung AS, Kimball J, Min E, Wang JC. Endoscopic spine surgery-increasing usage and prominence in mainstream spine surgery and spine societies. J Spine Surg. 2020;6(S1):S14-S18. doi:10.21037/jss.2019.09.16.

90. Soo ES, Sourabh C, Ho LS. Posterolateral endoscopic lumbar decompression rotate-to-retract technique for foraminal disc herniation: a technical report. Biomed Res Int. 2019;2019:5758671. doi: $10.1155 / 2019 / 5758671$. 
91. Eun SS, Chachan S, Lee SH. Interlaminar percutaneous endoscopic lumbar discectomy: rotate and retract technique. World Neurosurg. 2018;118:188-192. doi:10.1016/j.wneu.2018.07.083.

92. Shim HK, Choi KC, Cha KH, Lee DC, Park C-K. Interlaminar endoscopic lumbar discectomy using a new 8.4-mm endoscope and nerve root retractor. Clin Spine Surg. 2020;33(7):265-270. doi:10.1097/BSD.0000000000000878.

93. Sluijter ME, van Kleef M, Barendse GA, Weber W. Thermal transport during radiofrequency current therapy of the intervertebral disc. Spine. 1998;23(6):745. doi:10.1097/00007632-19980315000022.

94. Kapural L, Hayek S, Malak O, Arrigain S, Mekhail N. Intradiscal thermal annuloplasty versus intradiscal radiofrequency ablation for the treatment of discogenic pain: a prospective matched control trial. Pain Med. 2005;6(6):425-431. doi:10.1111/j.15264637.2005.00073.x.

95. Ramírez-León JF, Rugeles-Ortiz JG, Barreto-perea JA, Alonso-cuéllar GO. Intradiscal temperature variation resulting from radiofrequency thermal therapy. Cadaver study. Article in Spanich Acta Ortop Mex. 2014;28(12-18).

96. Zhou C, Zhang G, Panchal RR, et al. Unique complications of percutaneous endoscopic lumbar discectomy and percutaneous endoscopic interlaminar discectomy. Pain Physician. 2018;21(2):E105-E112.

97. Yörükoğlu AG, Göker B, Tahta A, et al. Fully endoscopic interlaminar and transforaminal lumbar discectomy: analysis of 47 complications encountered in a series of 835 patients. Neurocirugía. 2017;28(5):235-241. doi:10.1016/j.neucir.2017.03.003.

98. Gioffrè G, Impusino A, Tacconi L. Retroperitoneal hematoma after minimally invasive lumbar discectomy: is the percutaneous endoscopic approach really safe? J Neurosurg Sci. 2019;63(2):231-233. doi:10.23736/S0390-5616.17.04156-X.

99. Poutoglidou F, Metaxiotis D, Saloupis P, Mpeletsiotis A. Operative treatment of adult pyogenic spondylodiscitis: a retrospective study of 32 cases. Cureus. 2021. doi:10.7759/cureus.14820.

100. Urquhart JC, Gurr KR, Siddiqi F, Rasoulinejad P, Bailey CS. The impact of surgical site infection on patient outcomes after open posterior instrumented thoracolumbar surgery for degenerative disorders. J Bone Joint Surg Am. 2021; Publish Ahead of Print. doi:10.2106/JBJS.20.02141.

101. Wu N, Shao J, Zhang Z, et al. Factors and predictive model associated with perioperative complications after long fusion in the treatment of adult non-degenerative scoliosis. BMC Musculoskelet Disord. 2021;22(1):483. doi:10.1186/s12891-021-04361-y.

102. O'Toole JE, Eichholz KM, Fessler RG. Surgical site infection rates after minimally invasive spinal surgery. J Neurosurg Spine. 2009;11(4):471-476. doi:10.3171/2009.5.SPINE08633.

103. Xu J, Zhang L, Bu R, Liu Y, Lewandrowski K-U, Zhang $\mathrm{X}$, et al. Minimally invasive debridement and drainage using intraoperative CT-Guide in multilevel spondylodiscitis: a long-term follow-up study. BMC Musculoskelet Disord. 2021;22(1):120. doi:10.1186/s12891-021-03988-1.

104. Yeung A, Lewandrowski KU. Early and staged endoscopic management of common pain generators in the spine. J Spine Surg. 2020;6(Suppl 1):S1-S5. doi:10.21037/jss.2019.09.03.
105. Telfeian AE MD P. A retrospective evaluation of the clinical success of transforaminal endoscopic discectomy with foraminotomy in geriatric patients. Pain Phys. 2013;16(3):225-229. doi:10.36076/ppj.2013/16/225.

106. Jasper GP, Francisco GM, Telfeian A. Outpatient, awake, ultra-minimally invasive endoscopic treatment of lumbar disc herniations. R I Med J. 2013;97(47-49).

107. Jasper GP, Francisco GM, Telfeian AE. Transforaminal endoscopic discectomy with foraminoplasty for the treatment of spondylolisthesis. Pain Physician. 2014;17(6):E703-8.

108. Telfeian AE, Jasper GP, Francisco GM. Transforaminal endoscopic treatment of lumbar radiculopathy after instrumented lumbar spine fusion. Pain Physician. 2015;18(2):179-184.

109. Telfeian AE, Jasper GP, Oyelese AA, Gokaslan ZL. Technical considerations in transforaminal endoscopic spine surgery at the thoracolumbar junction: report of 3 cases. FOC. 2016;40(2):E9. doi:10.3171/2015.10.FOCUS15372.

Funding: The authors received no financial support for the research, authorship, and/or publication of this article.

\section{Declaration of Conflicting Interests: The} authors have no direct (employment, stock ownership, grants, patents), or indirect conflicts of interest (honoraria, consultancies to sponsoring organizations, mutual fund ownership, paid expert testimony). The authors are not currently affiliated with or under any consulting agreement with any vendor that the clinical research data conclusion could directly enrich. This manuscript is not meant for or intended to endorse any products or push any agenda other than the associated clinical outcomes with the endoscopic decompression surgery. The motive for compiling this clinically relevant information is by no means created and/or correlated to directly enrich anyone due to its publication. This publication was intended to substantiate contemporary endoscopic spinal surgery concepts to facilitate technology advancements.

Corresponding Author: Kai-Uwe Lewandrowski, Center for Advanced Spine Care, Tucson, AZ, USA; business@tucsonspine.com

Published 27 December 2021

This manuscript is generously published free of charge by ISASS, the International Society for the Advancement of Spine Surgery. Copyright (C) 2021 ISASS. To see more or order reprints or permissions, see http:// ijssurgery.com. 